\title{
Vocations as a Source of Identity: Reciprocal Relations Between Big Five Personality Traits and RIASEC Characteristics Over 15 Years
}

\author{
Bart Wille and Filip De Fruyt \\ Ghent University
}

\begin{abstract}
Although work is a core part of life, the direction of influence from personality to work has typically been conceived as only unidirectional. The present study aims to contribute to the literature by considering reciprocal relations between personality and occupational characteristics, drawing on current perspectives from personality psychology (i.e., the social investment principle) and using a well-established framework to conceptualize career development (i.e., Holland's RIASEC theory). For this purpose, a longitudinal cohort of college alumni $(N=266)$ was tracked across a substantial and significant period in their professional career. Big Five personality traits and RIASEC occupational characteristics were assessed at the career start and 15 years later when their careers had unfolded. A combination of observed and latent variable analyses were used to disentangle the longitudinal and reciprocal relations between traits and occupational characteristics. Our results indicate that personality shapes and is shaped by our vocational experiences, suggesting that work can be a source of identity. The implications for theory and research on personality in the industrial and organizational literature are discussed alongside a number of practical implications for organizational and counseling settings.
\end{abstract}

Keywords: occupational socialization, reciprocal relations, Big Five, Holland model

Individuals often seek out, create, evoke, or are selected into experiences that are compatible and correlated with their personality (Caspi \& Bem, 1990; Roberts, 2007; Scarr \& McCartney, 1983; Snyder \& Ickes, 1985). In the work domain in particular, there is now evidence showing that people are interested in and tend to gravitate toward occupational environments that - at least to a certain extent-fit their personality traits (Barrick, Mount, \& Gupta, 2003; Betz, Borgen, \& Harmon, 2006; De Fruyt \& Mervielde, 1999; Gottfredson, Jones, \& Holland, 1993; Woods \& Hampson, 2010). But what happens with individuals once they are in such environments? Do they adapt to the specific environmental demands that are characteristic for their occupation? In other words: How do our occupations shape who we are?

Frese (1982) wrote an article unambiguously entitled: "Occupational Socialization and Psychological Development: An Underemphasized Research Perspective in Industrial Psychology." The conclusion of his review was clear, stating that a significant dearth of research has addressed issues regarding occupational socialization, defined as those changes in the person that take place in and because of the work situation (Volpert, 1975). Interestingly, more than 20 years later, Judge and colleagues came to the same conclusions in their review on the contributions of personality to organizational behavior (Judge, Klinger, Simon, \& Yang, 2008). They specifically noted that despite recent advances in the person-

This article was published Online First November 4, 2013

Bart Wille and Filip De Fruyt, Department of Developmental, Personality, and Social Psychology, Ghent University, Ghent, Belgium.

Correspondence concerning this article should be addressed to Bart Wille, Department of Developmental, Personality, and Social Psychology, Ghent University, H. Dunantlaan 2, B-9000 Ghent, Belgium. E-mail: bart.wille@ugent.be ality literature on trait development, "much remains to be known about the role work plays in changes of personality" (p. 1994).

In contrast to the well-established findings concerning occupational selection, to date we have no satisfying answer to the fundamental question of whether and how work environments influence the development of basic psychological features, such as personality traits. Two principal reasons can be identified for this lack of research initiatives. First, studies on work socialization should also treat personality traits as dependent variables in addition to their more familiar status of predictor variables, therefore acknowledging that traits have the potential to change over time. For some, this may be a delicate perspective in industrial and organizational (I/O) psychology, as evidence for the stability of traits has earlier been put forward as an important step in the emerging consensus about the usefulness of personality and personality assessment in organizational contexts (Judge et al., 2008). Second, the study of work socialization processes requires very specific research designs that are challenging to carry out. As occupational socialization is a process that unfolds over time, one needs a longitudinal design with repeated measurements of both personal as well as occupational characteristics to capture the dynamics between both. Moreover, the time interval has to be large enough, as changes in personality traits typically occur at a modest rate and over relatively long time intervals (e.g., 10 years; Roberts \& Wood, 2006). Finally, it has been argued that the study of occupational socialization requires job analysis instruments that are embedded in psychological theories relevant for the study of development. Specifically, it is necessary to use measures of job characteristics that are psychologically meaningful and theoretically consistent (Frese, 1982).

The present study is unique in that it can draw on a research program that meets these high standards. We specifically depart from a well-documented college alumni project in which participants are tracked across a substantial and crucial period in their vocational lives, 
that is, the first 15 years of their professional careers. We start this study where previous research on person-occupation relationships left off, that is, by reexamining patterns of occupational selection (De Fruyt \& Mervielde, 1999). Using these findings as a starting point, the focus of the present investigation is on occupational socialization, framed in the theory of work adjustment (Dawis \& Lofquist, 1984). Work adjustment theory specifies two directions of influence between people and their work environment. On one hand, there is "active adjustment," or briefly activity, whereby environments change in reaction to people's personal characteristics. Note that from a long-term career perspective, this idea of changing environments can encompass both changes in one's current job environment (e.g., job crafting) as well as one changing to a new environment (e.g., external mobility). On the other hand, "reactive adjustment," or reactivity, refers to people acting on themselves (e.g., by changing interests, values, etc.) in reaction to work environments. In the present study, we specifically examine whether and how early career occupational characteristics predict subsequent changes in personality traits (i.e., reactivity effects), and vice versa, that is, whether and how personality traits predict changes in occupational characteristics over time (i.e., activity effects). Finally, codevelopment of personal and occupational characteristics are investigated through patterns of correlated change, describing whether and how changes in personality traits are associated with simultaneous changes in occupational characteristics over the same time interval.

Our study contributes to the literature in several ways. Although the idea of occupational socialization has been around in I/O psychology theory for over three decades (e.g., Frese, 1982), and even longer in the sociological literature (e.g., Van Maanen, 1976), very little empirical work has been done up until now to challenge these propositions. The present study offers a unique possibility to test the reciprocal relations between personality traits and work environments, whereas previous research has exclusively considered the unidirectional associations between both (e.g., Judge, Higgins, Thoresen, \& Barrick, 1999; Woods \& Hampson, 2010). Theoretically, we propose an integration of recent perspectives from the personality literature (e.g., social investment principle; Roberts, Wood, \& Smith, 2005) and established theory from vocational psychology (e.g., Holland's vocational type theory; Holland, 1985). As we discuss, cross-fertilization of these perspectives allows for a better understanding of the occupational socialization phenomenon for both personality and applied psychologists. For the latter, it is important to acknowledge that personality traits are not essentially fixed, but continue to develop and change throughout adulthood in and in response to work environments. Personality psychologists, however, should acknowledge that work as a central life domain is not something uniform but that substantial differences exist between work environments in terms of underlying role demands that may differentially influence trait change.

\section{Personality Trait Change in Adulthood}

The definition of occupational socialization implies that (a) working adults change over time and (b) work environments influence these changes. A substantial body of research now indicates that personality traits continue to change during adulthood, with the preponderance of change occurring between the ages of 20 and 40 years (Roberts, Robins, Caspi, \& Trzesniewski, 2003). Normative developmental changes, such as the tendency of people to become more agreeable, conscientious, and emotionally stable, have been observed in multiple birth cohorts and nations, using both longitudinal and cross-sectional designs (McCrae \& Terracciano, 2005; Roberts et al., 2005).

Diverging theoretical explanations exist, however, to account for these normative trait changes. From the perspective of the five-factor theory of personality (McCrae \& Costa, 2003), these normative changes result uniquely from a specific genetic predisposition to change, independent of environmental influences. From an alternative perspective, environmental approaches to trait change, such as the social investment principle (Roberts et al., 2005), posit that investment in social institutions and roles promotes personality development across adulthood. The central hypothesis in this perspective is that age-graded social norms, such as entering a committed relationship or the workforce, drive personality in the direction of functional maturity, that is, greater Emotional Stability, Agreeableness, and Conscientiousness. The underlying mechanism involves a process of role taking across different life domains, including work (Wood \& Roberts, 2006). When the individual commits to a social role, his or her personality shifts to reflect the expectancies of that role. In terms of work role investment, it is presumed that as individuals become increasingly committed to their career, they should experience changes in their personality traits that generally accommodate the demands of the workplace. Hereby, it is generally assumed that traits such as Agreeableness, Emotional Stability, and especially Conscientiousness accommodate workplace functioning (Hudson, Roberts, \& Lodi-Smith, 2012). Drawing on this social investment principle, Hudson and colleagues (2012) recently showed that increases in social investment in work (measured as a composite of job involvement, work centrality, and organizational citizenship behavior) were associated with increases in Conscientiousness. No significant associations were found, however, for the other five-factor personality model (FFM; McCrae \& Costa, 1987) traits.

Findings supporting social investment perspectives are informative for applied psychologists as they indicate that personality traits continue to change throughout adulthood and that work experiences can play a role herein. What this perspective seems to disregard, however, is that the work role is not at all uniform and that underlying role demands can vary substantially across different occupational environments. It is now a well-established fact in the I/O literature that job type is a significant moderator of personality-performance associations (Penney, David, \& Witt, 2011). Research has, for instance, indicated a positive association between Agreeableness and performance in jobs involving strong interpersonal interactions (Mount, Barrick, \& Stewart, 1998). However, a negative association has also been identified between Agreeableness and success in managerial functions (Boudreau \& Boswell, 2001). Findings such as these indicate that traits that are accommodating in one vocational environment may be of less use or even a hindrance in others. The major implication is that the effect of work role investment on personality change probably depends on the specific requirements that are characteristic for a given work environment.

\section{Occupational Environments and Trait Change}

Where applied psychologists can inform personality researchers is in providing validated and comprehensive models that can account for these differences among occupational environments. The most widely used and researched model of occupational 
environments is contained in Holland's theory of vocational personalities and work environments (Holland, 1958, 1996, 1997).

Six occupational environments are described in this model that pose very different requirements to individual employees (Holland, 1997). In the Realistic (R) environment, the focus is on manipulating things; these can be machines, plants, or animals. This environment fosters technical competencies and achievements and encourages workers to see the world in simple, tangible, and traditional terms. By contrast, workers in Social (S) environments mainly deal with other people to cure, develop, or inform them. This environment fosters social competencies and encourages people to see the world in flexible ways. Investigative (I) environments are dominated by environmental demands and opportunities that entail observation and creative investigation of physical, biological, or cultural phenomena. This environment fosters scientific competencies and achievements and encourages workers to see the world in complex, abstract, and original ways. Workers in Enterprising (E) environments are required to persuade and/or manipulate others in order to attain organizational or selfinterest goals. This environment fosters enterprising competencies and achievements, and workers are encouraged to see the world in terms of power, status, and responsibility. The Artistic (A) work environment is dominated by demands and opportunities that entail ambiguous, free, unsystematized activities and competencies to create art forms or products. Artistic competencies and achievements are stimulated, and workers in these environments are encouraged to see the world in complex, independent, and unconventional ways. Finally, central in the Conventional (C) work environment are demands and opportunities that entail the explicit, ordered, systematic manipulation of data such as keeping records, reproducing materials, organizing data, and operating business and data processing equipment. This environment fosters conventional competencies and achievements, and workers are encouraged to see the world in conventional, stereotyped, and constricted ways.

Holland's person-environment fit theory is best known as a theory of occupational selection that proposes that people gravitate to work (or educational) environments that match their personal characteristics (i.e., traits and interests). It is far less widespread, however, that this theory also proposes reciprocal effects. People in Enterprising work environments, for instance, "acquire or are reinforced for traits such as ambition, energy, assertiveness, sociability, etc." (Holland, 1997, p. 47). These "secondary effects," which essentially describe processes of occupational socialization, are a central but still heavily underexposed aspect of Holland's theory.

How can investment in these various occupational environments lead to trait change? Theoretical approaches dedicated to explain how situational demands can shape an individual's personality assume that sustainable changes in traits are usually preceded by behavioral changes (Fleeson \& Jolley, 2006; Roberts, 2006, 2009; Roberts \& Jackson, 2008). The key idea in the sociogenomic model of personality (Roberts \& Jackson, 2008) is that environmental experiences affect personality traits in a bottom-up fashion. Specifically, it is assumed that role demands create a reward structure promoting self-regulated and consistent changes in behavior that, if extended, may cause changes in traits through a bottom-up process (Bleidorn, 2012). That is, behavioral changes (besides changes in thoughts and feelings) are supposed to take on a mediational role as they account for the path through which prolonged environmental effects will change neuroanatomical structures or gene expression, and thus change personality traits (Roberts, 2009).

The sociogenomic model of personality traits further describes at a microlevel how and which are the experiences that may change personality traits (see Figure 1). For this purpose, this model focuses on the state-level manifestations of personality traits. Traits are manifested through stable, enduring patterns of states (thoughts, feelings, and behaviors) and are responsible for future states. This implies that environmental experiences can affect personality traits only indirectly, mediated through personality states (see Path A in Figure 1). Importantly, traits are not the only causes of state-level behaviors, thoughts, and feelings. These states may be partly due to the specific situation or experience that a person is embedded in (see Path B in Figure 1), and the focus on states due to both traits and experiences provides a straightforward explanation for variability in behavior (Roberts \& Jackson, 2008). Note that such variability in states does not invalidate the existence of a trait because experiences do not directly influence personality traits. Instead, experiences can affect personality traits only indirectly, mediated through personality states (see Paths A and B in Figure 1). Trait change is thus thought to occur by relatively consistent experiences that lead to lasting changes in the way one behaves, thinks, or feels. These long-term shifts may occur unconsciously. For example, being around extraverted colleagues may act as a contagion, where one's assertiveness increases due to one's desire to fit in and not stand out.

Imagine someone in a strong Enterprising vocational environment (e.g., a management function), where the focus is on the manipulation of others to attain organizational or self-interest goals (Holland, 1997). These work role demands create an atmosphere in which this individual is stimulated to engage in Enterprising activities, such as sales or leading others. Besides behaving in this role-congruent manner, this individual is also encouraged to see him- or herself as aggressive, popular, self-confident, and as possessing leadership and communication abilities (Holland, 1997). Over time, it can be expected that these characteristic behaviors, thoughts, and feelings translate into the acquisition or reinforcement of traits such as ambition, assertiveness, energy,

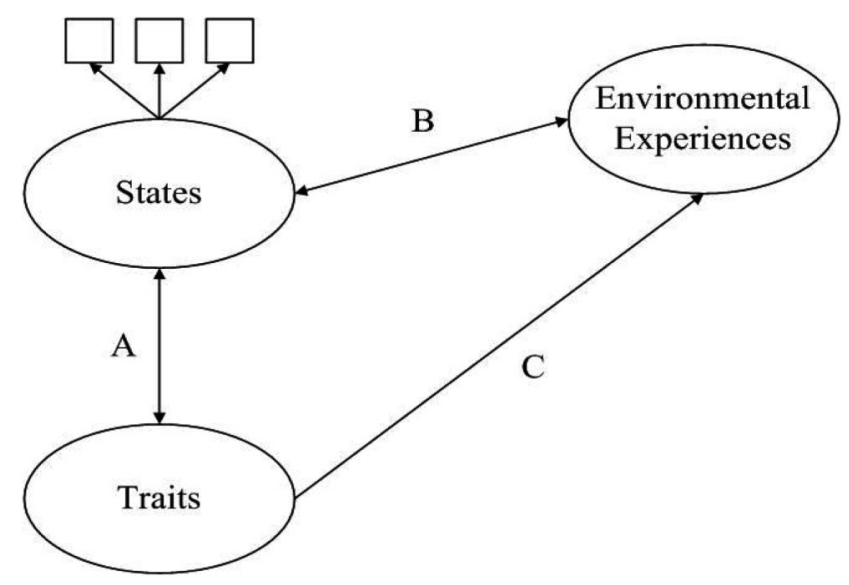

Figure 1. Sociogenomic model of personality traits that illustrates how environmental experiences might influence trait change. 
dominance, and sociability. Note that these are probably also the traits that got people selected into this Enterprising environment in the first place (De Fruyt \& Mervielde, 1999). Although these occupational socialization effects and the theoretical mechanisms underlying them seem very plausible, to date no empirical work has been done to systematically test this principle of reciprocity.

\section{The Present Study}

The present study has the general objective of extending prior research on the associations between personality and occupational characteristics by looking beyond selection effects. Specifically, we use these findings concerning occupational selection as a basis for more innovative hypotheses and research questions regarding the reciprocal associations between personality and occupations over time. De Fruyt and Mervielde (1999) demonstrated in a sample of college alumni that personality traits, measured 3 months prior to graduation, predicted occupational selection 1 year later. Neuroticism was not significantly related to the environmental types, whereas Extraversion was related to employment in Enterprising $(r=.35, p<.01)$, Social $(r=.25, p<.01)$ and, to a lesser extent, Conventional $(r=.13, p<.05)$ environments. Openness to Experience was positively correlated with employment in Social $(r=.28, p<.01)$, Artistic $(r=.25, p<.01)$, and Enterprising environments $(r=.12, p<.05)$, but negatively correlated with Realistic $(r=-.15, p<.05)$ environments. Agreeableness was negatively related to working in jobs with Artistic $(r=-.15, p<.05)$ and Enterprising $(r=-.16, p<.05)$ features. Finally, Conscientiousness was negatively related to working in Artistic jobs $(r=-.12, p<.05)$, but correlated positively with employment in Enterprising $(r=.17, p<.05)$, Conventional $(r=.15, p<.05)$, and Realistic $(r=.12, p<.05)$ environments. These correlations, although moderate, supported the idea of a match between occupational characteristics and FFM traits (De Fruyt \& Mervielde, 1999).

Here, we present a follow-up of this research, and particularly focus on the processes that follow occupational selection. Our research model is illustrated in the middle part of Figure 2 (dotted lines). Our primary focus lies on the issue of occupational socialization: Do people's personality traits change under the influence of those occupational environments that they selected or were selected in? In terms of the theory of work adjustment, we label these socialization effects reactivity (see Path $\mathrm{B}_{2}$ in Figure 2). In addition, we also examine the effects of initial personality trait levels on subsequent change in occupational characteristics. Do people further adjust their occupational environment as a function of their personality traits? These effects are labeled activity (see Path $\mathrm{B}_{1}$ in Figure 2). Finally, given that both occupational characteristics and personality traits are presumed to change over time, we also investigate patterns of correlated change (see Path $\mathrm{C}$ in Figure 2).

Because we argue that these reciprocal effects over time are connected to initial selection effects, we also reexamine the effects of initial personality traits on initial occupational environments (see Path A in Figure 2). Although these selection effects have been examined before (De Fruyt \& Mervielde, 1999), it is important to reestablish these in our restricted longitudinal sample, as these results will serve as a basis for the innovative hypotheses concerning reciprocal relations.

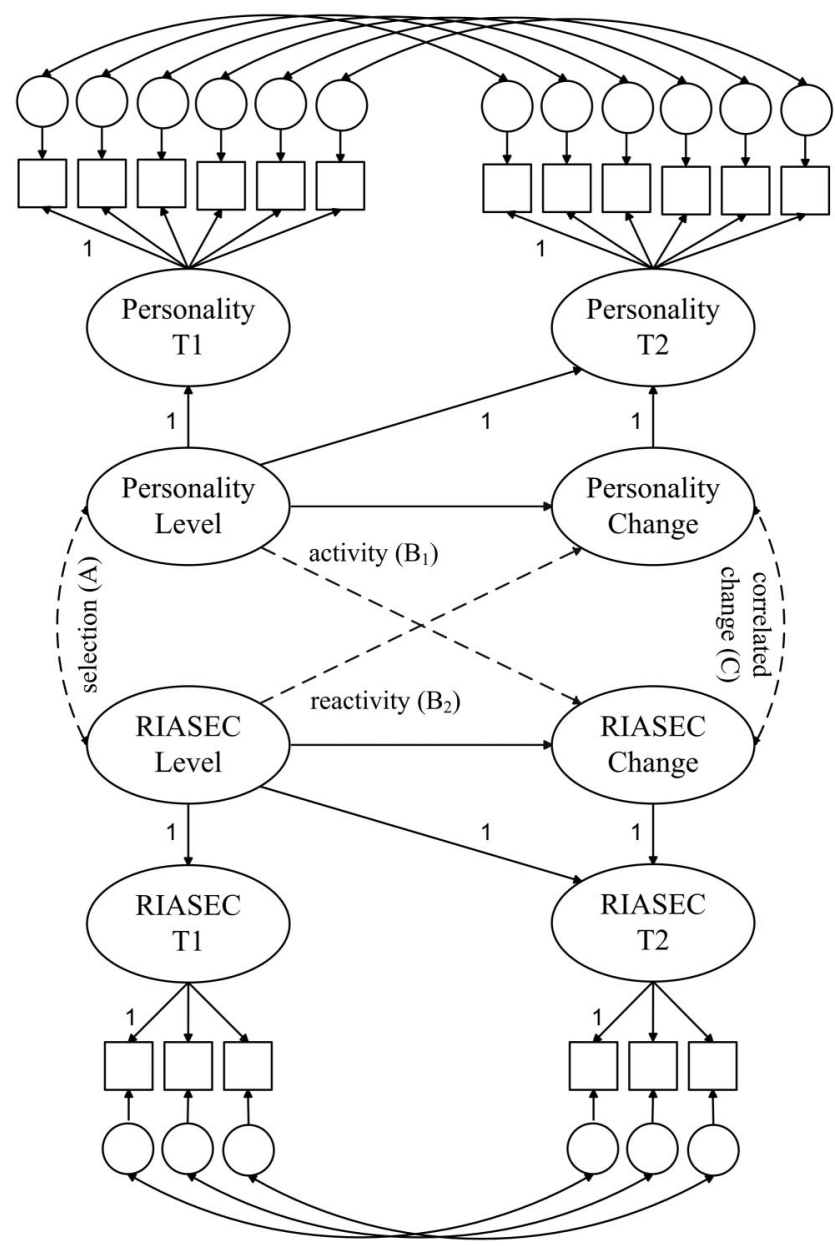

Figure 2. A schematic representation of the central research questions (dotted lines in the middle section of the figure) and the structural equation models (SEMs) that were constructed to test these. SEMs are multivariate latent change models (LCMs) that consist of a relatively standard specification of RIASEC and five-factor personality model personality factors at two measurement occasions. Three item parcels (boxes) define the occasion-specific latent RIASEC variables (e.g., Realistic T1 and Realistic T2). The fixed-1 regression coefficients define the latent RIASEC Level and RIASEC Change variables, which are allowed to covary. For the personality factors, six facet scales instead of three item parcels are used to define the latent variables. Finally, in both the RIASEC and the personality LCMs, factor loadings for the observed indicator variables are constrained equal (invariant) over time, and residuals of these indicators are allowed to covary across occasions to reflect stability in systematic errors over time. $\mathrm{T} 1=$ Time 1; T2 = Time 2; RIASEC = Realistic, Investigative, Artistic, Social, Enterprising, Conventional.

\section{Hypotheses}

Past research suggests that reactivity/socialization and selection effects are intimately related. There is an overlap between the experiences selected through personality traits and the changes that result from those same experiences (Neyer \& Lehnart, 2007; Roberts, Caspi, \& Moffitt, 2003; Robins, Noftle, Trzesniewski, \& Roberts, 2005). That is, life experiences do not impinge themselves on people in a random fashion. Rather, 
selection effects set in motion socialization effects, wherein the personality traits that people already possess are deepened and elaborated by trait-correlated experiences. This pattern is described as the corresponsive principle and has been presented in the literature as the most probable type of personality change that occurs over the life course (Roberts, Wood, \& Caspi, 2008). Specifically, experiences that are in line with one's dispositions (selection) will be viewed as validating and rewarding, thus resulting in changes in the traits (socialization) that brought the person to the experience in the first place. For example, individuals who score higher on Extraversion are more likely to select occupations with strong Enterprising characteristics (De Fruyt \& Mervielde, 1999). On the basis of this corresponsive principle, engagement in these occupations should be associated with changes in Extraversion such that people deepen this trait (i.e., become more extraverted over time). This brings us to the following hypothesis concerning reactivity/occupational socialization effects:

Hypothesis 1: Selection and reactivity/socialization effects are linked by a corresponsive principle. That is, traits that got people selected into certain occupational environments are the most likely to change under the influence of these same occupational characteristics in such a way that these traits are intensified and deepened.

Besides selecting a fitting environment, gravitational theories typically assume that, over the course of one's career, people actively shape their work environment in order to enhance person-environment fit (i.e., active adjustment). Two main mechanisms can be discerned when this idea of activity is framed within a career context. First, people may decide to leave their work environment and change it for another in order to enhance congruence. Research has, for instance, indicated that career changers tend to choose new jobs that are more congruent with their personality profiles (Donohue, 2006; Oleski \& Subich, 1996). Second, individuals may also consciously as well as unconsciously attempt to modify their concrete work environment in order to maximize fit. This is in line with the ideas behind job crafting (Wrzesniewski \& Dutton, 2001) and job sculpting (Bell \& Staw, 1989), which entail that individuals can affect their day-to-day work experience by altering the tasks they do, organizing their work differently, or by changing the nature of the relationships they maintain with others (Wrzesniewski \& Dutton, 2001). Sutin and Costa (2010), for instance, found that individuals high on Emotional Stability occupied jobs that are characterized by higher levels of decision latitude and that emotionally stable individuals actively shaped their jobs over the next 10 years to include even more decisionmaking latitude. This indicates that as individuals progress through their careers, they mold their everyday occupational experiences to fit their personality. Moreover, the example cited above indicates that this activity mechanism is connected with initial selection effects. Specifically, this suggests that selection effects at the beginning of the career should persevere over time. This means that, over time, individuals are expected to selectively strengthen those occupational characteristics that were also preferred at the career start. If, for instance, we find Extraversion to be positively associated with Enterprising char- acteristics at the beginning of the career, then we also expect individuals high on Extraversion to demonstrate increases in Enterprising characteristics over the next 15 years. Conversely, if a negative association between certain traits and specific occupational characteristics at the career start exists, then individuals are expected to further adjust their work environment over time in order to downsize these disliked occupational characteristics. This is summarized in the following hypothesis:

Hypothesis 2: Selection effects are also reflected in the activity effects. That is, associations between traits and occupational characteristics at the beginning of the career will also be reflected in the prospective effects of trait levels on subsequent changes in occupational characteristics.

Selection effects lead a person to have an experience whereby the experience then leads to changes in personality traits. However, as a person changes in response to an experience, they are likely to select into and evoke different experiences consistent with their personality. This indicates a bidirectional and dynamic process in which changes in one construct (a personality trait) leads to changes in another (an experience), and then back again (personality trait change). The reciprocal effect paths in our research model (see Paths $B_{1}$ and $B_{2}$ in Figure 2) address the (static) prospective effects of initial trait levels on subsequent changes in occupational characteristics, and vice versa. Correlated change (see Path $\mathrm{C}$ in Figure 2) addresses the (dynamic) association between changes in traits and changes in occupational characteristics over time. Correlated change is essential to understanding life-span development, as it provides evidence of personality and social roles enhancing one another over time (Hertzog \& Nesselroade, 2003; Scollon \& Diener, 2006; Sliwinski, Hofer, \& Hall, 2003). The present study is the first to shed a light on the codevelopment of FFM traits and RIASEC occupational environments over time. We expect these patterns of correlated change to follow the corresponsive principle; that is, we expect these correlations between change factors to reflect the correlations between initial level factors. This specifically means that changes in occupational characteristics should be associated with changes in those personality traits that got people selected into these environments in the first place. If, for instance, we find Extraversion to be positively related to the selection of Enterprising occupations, then changes in Enterprising characteristics should also be positively associated with changes in Extraversion over time. This translates into the following hypothesis:

Hypothesis 3: Selection and correlated change are linked by a corresponsive principle. That is, correlations between changes in personality traits and occupational characteristics are expected to reflect the initial level associations between both.

\section{Method}

\section{Design and Participants}

To test these hypotheses, data were used from a longitudinal research program on individual differences and career unfolding in a well-documented college alumni sample. Previous studies have used data from this research project to illustrate the importance of FFM personality traits regarding initial job choice (De Fruyt \& Mervielde, 1999), early career work adjustment (De Fruyt, 2002), career transitions (Wille, Beyers, \& De Fruyt, 2012; Wille, De 
Fruyt, \& Feys, 2010) and career success attainment (Wille, De Fruyt, \& De Clercq, 2013; Wille, De Fruyt, \& Feys, 2013).

In 1994, 934 final-year undergraduates from various faculties enrolled in this study filling out personality inventories 3 months prior to graduation (for a thorough description of the sample, see De Fruyt \& Mervielde, 1999). One year later (1995), a first follow-up was conducted asking participants to report on their current status and nature of employment 1 year after graduation. A second follow-up was organized in 2009, reassessing participants' personality 15 years after the first assessment and gathering information on their past career trajectories and levels of success attainment. Finally, a third follow-up was organized in 2010, now focusing on participants' current nature of employment after 15 years in the labor market. The present study is unique in that it addresses the reciprocal relations between FFM traits and RIASEC occupational characteristics over the entire time interval captured by this longitudinal study. Data are used from all four assessment points, although we here consider the initial assessments of personality (1994) and employment situation (1995) as Time 1 (T1) assessments, and the reassessments of personality (2009) and employment situation (2010) are considered Time 2 (T2) assessments.

The issue of dropout is inherent to longitudinal research designs, especially when time intervals are large. In the design presented here, dropout was possible on three occasions (1995, 2009, 2010), and participants were invited to participate even when they did not respond on earlier occasions. Two hundred sixty-six participants were included for the present study who all provided T1 ratings of personality and T2 RIASEC assessments of their current employment situation. Of these 266 participants, $216(81.2 \%)$ also provided valid T2 ratings of personality, and 179 (67.3\%) also provided $\mathrm{T} 1$ employment assessments. We first examined attrition effects by inspecting whether and how our selected sample of 266 participants differs from the original sample in terms of baseline (T1) personality traits and occupational characteristics. With regard to FFM personality traits, we found that, on average, the "continuers" $(n=266)$ scored significantly higher than the "dropouts" $(n=668)$ on T1 Extraversion, $t(931)=-2.12, p<.05$; and T1 Openness to Experience, $t(931)=-2.10, p<.05$, although the effect sizes were small ( $d=-.15$ and -.21 , respectively). For those who had valid T1 assessments of occupational characteristics, we also inspected whether continuers $(n=178)$ differed from dropouts $(n=377)$ in terms of baseline RIASEC scores. Only one significant difference was found: On average, we found continuers to score higher on $\mathrm{T} 1$ social characteristics compared with dropouts, $t(548)=-2.23, p<.05$, although this difference was again modest $(d=-.20)$.

We also inspected whether these mean differences between the original sample and the selected sample influenced the pattern of correlations between $\mathrm{T} 1$ personality and T1 vocation scores. After applying Fisher's $r$ to Z transformation, pairwise comparisons of (a) the correlations between Extraversion and the six RIASEC scales, (b) the correlations between Openness to Experience and the six RIASEC scales, and (c) of the correlations between Social occupational characteristics and the Big Five dimensions all indicated that the mean differences between both samples had no significant effect on the interrelations among these variables.

Next, we closely examined the pattern of missing values in our selected longitudinal sample. Schafer and Graham (2002) recommend the use of maximum likelihood (ML) estimation procedures that take into account all the available data for each participant, so that missing information can then be partially recovered from earlier or later waves (see also Schafer, 1997). To justify the use of ML estimation, however, the data should be missing (completely) at random (MCAR), which can be tested using Little's (1988) multivariate test implemented in the SPSS Missing Value Analysis module (Howell, 2007). When applied to the 22 variables included in our longitudinal data set (five traits, six RIASEC dimensions, two assessment points), Little's test revealed missings in this sample of 266 participants to be completely at random: MCAR, $\chi^{2}(228)=212.60, p>.05$, showing that the probability of nonresponse and/or dropout in this selected sample is unrelated to any of the assessed study variables.

\section{Sample Characteristics}

The study sample consisted of 135 male and 131 female alumni. Although all highly educated, participants were heterogeneous in their vocational interests, with alumni representing various college faculties including Industrial engineering $(n=54)$; Philosophy, History, and Languages $(n=43)$; Law $(n=32)$; Sciences $(n=$ 20); Applied sciences $(n=27)$; Economics $(n=25)$; Psychology and Educational sciences $(n=36)$; Applied Biological sciences $(n=4)$; and Political and Social sciences $(n=25)$. Participants' mean age at T1 (1994) was 22.35 years $(S D=1.65)$. Qualitative information was used to get a sense of the types of jobs that participants were in. Specifically, 163 alumni provided sufficiently detailed information consisting of a self-report job title and a brief job description, which we recoded into formalized $\mathrm{O}^{*} \mathrm{NET}$ job titles (O*NET Resource Center, 2012) independently for both measurement occasions. Substantial diversity in job titles was observed at T1 and T2, with jobs held covering all six RIASEC domains, including Industrial Machinery Mechanic (Realistic), Biologist (Investigative), Fashion Designer (Artistic), Secondary School Teacher (Social), Sales Representative (Enterprising), and Insurance Policy Processing Clerk (Conventional). Comparing participants' O*NET job titles across time showed that almost one third (32.3\%) had the same job title in 2010 compared with 15 years earlier. When job titles were categorized on the basis of the first letter of their $\mathrm{O}^{*} \mathrm{NET}$ RIASEC letter codes, $45.4 \%$ of the respondents demonstrated stability in occupations held (i.e., kept the same primary RIASEC letter in their job code over time).

\section{Measures}

Personality traits. At both T1 (1994) and T2 (2009), FFM traits were assessed using the Dutch-validated version of the NEO Personality Inventory-Revised (NEO-PI-R; Costa \& McCrae, 1992; Hoekstra, Ormel, \& De Fruyt, 1996). The NEO-PI-R is a comprehensive personality questionnaire, measuring five broad and 30 more specific traits by means of 240 items that are to be scored on a 5-point Likert scale. The Dutch adaptation has satisfactory psychometric characteristics and factor loadings closely resembling the loading matrix reported in the normative U.S. NEO-PI-R manual (Costa \& McCrae, 1992, p. 44; De Fruyt \& Mervielde, 1999).

Occupational characteristics. Participants described their current work environments at T1 (1995) and T2 (2010) using the Dutch adaptation of the Position Classification Inventory (PCI), 
initially developed by Gottfredson and Holland (1991) and translated into Dutch by Hogerheijde, Van Amstel, De Fruyt, and Mervielde (1995). The PCI assesses the resemblance of work environments to Holland's theoretical RIASEC types. The PCI was developed to gauge the characteristics of the environment adequately and comprehensively (Gottfredson \& Holland, 1991; Holland, 1997). For this purpose, each environmental type is assessed with 14 items, covering the activities involved in the job, the traits and abilities required for the job, and the personal styles and values that are valued in the job. Each of the 84 items are scored on a 3-point Likert scale. The validity of this self-report vocation assessment was examined by inspecting the correlations between the PCI RIASEC scores and the O*NET-derived RIASEC scores $(n=163)$. A relatively high level of correspondence was observed between both assessment methods: At T1, corresponding RIASEC scales correlated .53 (Realistic; $p<.001$ ), .37 (Investigative; $p<.001$ ), .41 (Artistic; $p<.001$ ), .31 (Social; $p<.001$ ), .28 (Enterprising; $p<.001$ ), and .22 (Conventional; $p<.01$ ); at $\mathrm{T} 2$, these respective correlations were $.52, .42, .51, .49, .44$, and .24 (all $\mathrm{ps}<.001$ ). At both measurement occasions, the highest correlation between $\mathrm{PCI}$ and $\mathrm{O}^{*} \mathrm{NET}$ ratings were for corresponding RIASEC scales, which provides further support for the validity of PCI ratings.

Intercorrelations between all (observed) study variables and Cronbach's alpha internal consistencies are reported in Table 1.

\section{Analyses}

A combination of observed and latent variable analyses were conducted. First, in order to get a sense of the general patterns of stability and change in personality traits and work environments, test-retest correlations and repeated measures analyses of variance (ANOVAs) were computed using observed Big Five personality and RIASEC occupation scores. Next, we used latent change models (LCMs; McArdle, 1980; McArdle \& Nesselroade, 1994) to examine the central research questions of this study, that is, the associations (concurrent and prospective) between personality traits and work environments, as well as the concurrent longitudinal change between traits and occupations. An LCM uses two waves of data to estimate the intercept ("Level" factor) and slope ("Change" factor) of a variable over time, controlling for measurement error. Figure 2 contains the LCM used in the present study.

At each time point, latent variables were constructed to represent individuals' personality and RIASEC occupation scores. For the latent personality factors, NEO-PI-R facet scores (six per Big Five domain) were used as observed indicator variables. Latent occupational environment variables were created by parceling the PCI items within each RIASEC scale. To create each parcel, four to five scale items were averaged. Parcels tend to be more reliable and more normally distributed compared with single items and are thus better at meeting the assumptions of ML estimation (Allemand, Zimprich, \& Hertzog, 2007; Jackson et al., 2009). Additionally, parcels reduce the number of estimated parameters and, therefore, reduce the complexity of the second-order LCM, resulting in better model fit. Selecting the three highest loading items from a factor analysis created three parcels. These three items anchored each of the three parcels. The remaining items were distributed into each parcel by adding the fourth highest loading to the first parcel, the fifth highest to the second parcel, and so on until all the items were allocated (T. D. Little, Cunningham, Shahar, \& Widaman, 2002). As shown in Figure 2, second-order latent-level and change factors were then estimated from the $\mathrm{T} 1$ and T2 latent scores.

One of the advantages of LCMs is that they are tolerant of missing data. The fact that missingness in our longitudinal sample of 266 participants was completely at random allowed us to use the full information ML (FIML; Schafer \& Graham, 2002) approach to deal with these missings. FIML is a pragmatic missing data estimation approach for structural equation modeling that has been shown to produce unbiased parameter estimates and standard errors under MCAR. This procedure was moreover preferred over alternatives such as those using only complete case data $(n=147)$ or data imputation (e.g., expectation maximization), both of which can lead to biased estimates (Hox, 2000; Wothke, 2000). Specifically, this approach better represents the entire sample rather than just the subsample of alumni who have no missing data while still providing appropriate tests of statistical significance that reflect the amount of missing data for each variable. All latent variable analyses were conducted using LISREL 8.72 (Jöreskog \& Sörbom, 2004), which provides the root-mean-square error of approximation (RMSEA) to evaluate goodness of fit in case of FIML estimation. The main focus in the present study, however, was on the evaluation of the parameter estimates.

Another benefit of the LCM is that it lets us simultaneously estimate the latent correlation between $\mathrm{T} 1$ levels of personality and occupational characteristics (see Path A in Figure 1), the prospective relation between T1 levels and change over time (see Path B in Figure 1), as well as the simultaneous latent change between personality and occupational characteristics (see Path $\mathrm{C}$ in Figure 1), all uncontaminated by measurement error. LCMs, hence, cover all three fundamental research questions of the present study: Latent-level correlations address occupational selection effects, cross-lagged relations address activity (see Path $\mathrm{B}_{1}$ ) versus reactivity (see Path $\mathrm{B}_{2}$ ) effects, and, finally, latent change correlations address correlated change.

\section{Results}

\section{Developmental Aspects of Personality Traits and Occupational Characteristics}

Table 2 summarizes the general patterns of stability and change in Big Five personality traits and RIASEC environment dimensions over the 15-year interval. Regarding personality development, the findings show great correspondence with what has been reported in other samples of similar age (Roberts \& DelVecchio, 2000; Roberts, Walton, \& Viechtbauer, 2006). Our results first indicate moderate to strong levels of rank-order stability in personality traits, with test-retest correlations ranging between .48 $(p<.001)$ for Conscientiousness and $.69(p<.001)$ for Extraversion. Similarly, moderate to relatively high test-retest correlations were found for the six RIASEC occupation scales, varying between .23 ( $p<.01$; Enterprising characteristics) and $.51(p<$ .001; Artistic characteristics). Further, repeated measures ANOVAs indicated significant mean changes in four of the Big Five traits: On average, participants decreased in Neuroticism $(d=-.48, p<$ $.001)$ and Openness to Experience $(d=-.42, p<.001)$ while 


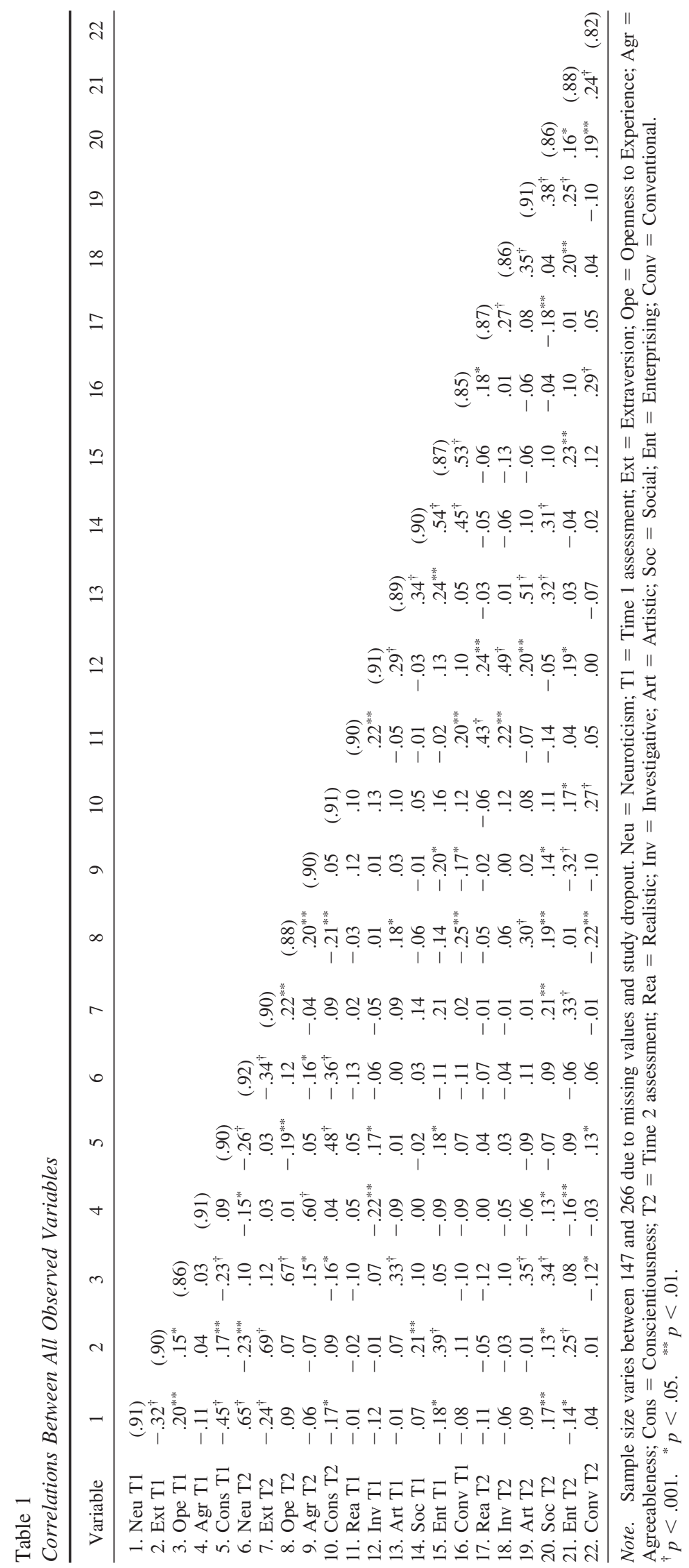


Table 2

Stability and Change Patterns in Big Five Personality Traits and RIASEC Occupational Characteristics

\begin{tabular}{|c|c|c|c|c|c|c|c|c|c|}
\hline \multirow[b]{3}{*}{ Variable } & \multicolumn{5}{|c|}{ Observed variables } & \multicolumn{4}{|c|}{ Latent variables } \\
\hline & \multirow{2}{*}{$\frac{\text { Test-retest }}{r}$} & \multicolumn{2}{|c|}{$\mathrm{T} 1$} & \multicolumn{2}{|c|}{$\mathrm{T} 2$} & \multirow{2}{*}{$\frac{\text { Mean change }}{d}$} & \multirow{2}{*}{$\frac{\text { Fit }}{\text { RMSEA }}$} & \multirow{2}{*}{$\frac{\text { Change level }}{r}$} & \multirow{2}{*}{$\frac{\text { Change }}{s^{2}}$} \\
\hline & & $M$ & $S D$ & $M$ & $S D$ & & & & \\
\hline \multicolumn{10}{|l|}{ Big Five traits } \\
\hline Neuroticism & $.65^{\dagger}$ & 2.82 & .43 & 2.62 & .41 & $-.48^{\dagger}$ & .05 & $-.47^{\dagger}$ & $.10^{\dagger}$ \\
\hline Extraversion & $.69^{\dagger}$ & 3.33 & .43 & 3.29 & .42 & -.09 & .08 & $-.39^{\dagger}$ & $.08^{\dagger}$ \\
\hline Openness to Experience & $.67^{\dagger}$ & 3.60 & .36 & 3.44 & .40 & $-.42^{\dagger}$ & .06 & $-.25^{*}$ & $.06^{\dagger}$ \\
\hline Agreeableness & $.60^{\dagger}$ & 3.42 & .41 & 3.50 & .34 & $.21^{* * *}$ & .07 & $-.61^{\dagger}$ & $.07^{\dagger}$ \\
\hline Conscientiousness & $.48^{\dagger}$ & 3.47 & .39 & 3.67 & .35 & $.54^{\dagger}$ & .07 & $-.60^{\dagger}$ & $.08^{\dagger}$ \\
\hline \multicolumn{10}{|l|}{ RIASEC characteristics } \\
\hline Realistic & $.43^{\dagger}$ & 0.44 & .45 & 0.29 & .35 & $-.39^{\dagger}$ & .00 & $-.57^{\dagger}$ & $.13^{\dagger}$ \\
\hline Investigative & $.49^{\dagger}$ & 1.27 & .50 & 1.28 & .40 & .02 & .07 & $-.62^{\dagger}$ & $.18^{\dagger}$ \\
\hline Artistic & $.51^{\dagger}$ & 0.74 & .45 & 0.71 & .43 & -.07 & .01 & $-.47^{\dagger}$ & $.19^{\dagger}$ \\
\hline Social & $.31^{\dagger}$ & 1.28 & .46 & 1.46 & .35 & $.46^{\dagger}$ & .01 & $-.68^{\dagger}$ & $.22^{\dagger}$ \\
\hline Enterprising & $.23^{* * *}$ & 0.88 & .43 & 1.18 & .40 & $.75^{\dagger}$ & .08 & $-.57^{\dagger}$ & $.19^{\dagger}$ \\
\hline Conventional & $.29^{\dagger}$ & 1.18 & .39 & 1.47 & .32 & $.85^{\dagger}$ & .06 & $-.65^{\dagger}$ & $.12^{\dagger}$ \\
\hline
\end{tabular}

Note. Observed variable analyses are based on $n=216$ for personality traits and $n=179$ for RIASEC occupation scales. Latent variable analyses are based on the entire sample $(N=266)$ using full information maximum likelihood. T1 $=$ Time 1 ; Time $2=$ Time 2 ; RMSEA $=$ root-mean-square error of approximation. RIASEC $=$ Realistic, Investigative, Artistic, Social, Enterprising, Conventional.

${ }^{\dagger} p<.001 .{ }^{*} p<.05 .{ }^{* * *} p<.01$.

simultaneously increased in Agreeableness $(d=.21, p<.01)$ and Conscientiousness $(d=.54, p<.001)$. Regarding the RIASEC occupation scales, four significant mean-level changes were observed: Whereas participants' occupations, on average, decreased in Realistic characteristics $(d=-.39, p<.001)$, mean-level increases were found in Social $(d=.46, p<.001)$, Enterprising $(d=.75, p<.001)$, and Conventional $(d=.85, p<.001)$ characteristics.

In addition to these observed variable analyses, 11 univariate LCMs were also estimated (see Latent variables section in Table 2). The results first indicated excellent to acceptable model fit indices for all univariate LCMs. Note that LISREL only reports RMSEA fit indices when missings are treated using FIML techniques and that $.00 \leq \mathrm{RMSEA} \leq .08$ indicates excellent to acceptable model fit (Browne \& Cudeck, 1993). Univariate LCMs further indicated significant negative correlations between latentlevel and change factors (see the Change level $r$ column in Table 2 ), indicating that higher initial scores were accompanied by stronger decreases or smaller increases over the next 15 years. Finally, before considering changes in personality traits and RIASEC occupation scales as dependent variables, it is appropriate to first test whether there is statistically significant variation in individual differences in change (Hudson et al., 2012). In this case, we checked for significant individual differences in change by testing for statistically significant variance in the latent change parameters. This requirement was met, as we found significant variance in the change factors for all Big Five personality traits and all RIASEC vocation scales (see the Change $s^{2}$ column in Table 2; all $p \mathrm{~s}<.001)$. Thus, ample differences in change existed in both sets of variables that could be predicted.

\section{Reciprocal Relations Over Time}

In a second step, the reciprocal associations between Big Five personality traits and RIASEC occupation scales were analyzed using a set of 30 ( 5 traits $\times 6$ vocation scales) multivariate LCMs.
Results first indicated adequately fitting models, with RMSEA indices ranging between .03 and .07. Parameter estimates are summarized in Table 3. Note that the threshold for significant path coefficients varies by model, due to the fact that each model estimates a separate variance-covariance matrix, and the subsequently estimated standard errors for each effect differ on the basis of these matrices.

Selection effects. Before testing our hypotheses regarding activity, reactivity, and correlated change, we reexamined the (static) associations at $\mathrm{T} 1$ between initial personality trait levels and starting levels of RIASEC occupational characteristics. These selection effects were used in the present study to evaluate the corresponsiveness of the (dynamic) long-term reciprocal relations between personality and work. Note that although these $\mathrm{T} 1$ associations are labeled concurrent, they do reflect predictive relations because personality traits were assessed 1 year prior to vocational characteristics. The results in Table 3 (columns A) indicated that all but initial Realistic occupational characteristics were significantly predicted by at least one T1 personality trait. Levels of Neuroticism negatively predicted initial Enterprising characteristics $(r=-.17, p<.05)$; Extraversion positively predicted initial Social $(r=.24, p<.01)$ and Enterprising characteristics $(r=.39, p<.001)$; Openness to Experience positively predicted initial Artistic $(r=.30, p<$ $.001)$ and Social characteristics $(r=.14, p<.05)$, and negatively predicted initial Conventional characteristics $(r=-.14$, $p<.05$ ); Agreeableness negatively predicted initial Investigative characteristics $(r=-.26, p<.01)$; and Conscientiousness positively predicted initial Investigative $(r=.20, p<.01)$ and Enterprising characteristics $(r=.17, p<.05)$.

Reactivity and activity effects. The bivariate LCMs simultaneously tested whether starting level occupational characteristics predicted subsequent changes in personality traits (i.e., reactivity effects; Path $B_{2}$ in Figure 2) and whether initial personality levels 
Table 3

Results From the Multivariate Latent Change Models

\begin{tabular}{|c|c|c|c|c|c|c|c|c|c|c|c|c|c|c|c|c|c|c|c|c|}
\hline \multirow[b]{2}{*}{ Vocation } & \multicolumn{4}{|c|}{ Neuroticism } & \multicolumn{4}{|c|}{ Extraversion } & \multicolumn{4}{|c|}{ Openness to Experience } & \multicolumn{4}{|c|}{ Agreeableness } & \multicolumn{4}{|c|}{ Conscientiousness } \\
\hline & $\mathrm{A}$ & $\mathrm{B}_{1}$ & $\mathrm{~B}_{2}$ & $\mathrm{C}$ & A & $\mathrm{B}_{1}$ & $\mathrm{~B}_{2}$ & $\mathrm{C}$ & A & $\mathrm{B}_{1}$ & $\mathrm{~B}_{2}$ & $\mathrm{C}$ & A & $\mathrm{B}_{1}$ & $\mathrm{~B}_{2}$ & $\mathrm{C}$ & A & $\mathrm{B}_{1}$ & $\mathrm{~B}_{2}$ & $\mathrm{C}$ \\
\hline enlistic & .06 & -.03 & $.20^{* *}$ & .12 & .00 & -.09 & .05 & .02 & -.07 & $-.15^{*}$ & .11 & .09 & 10 & -.07 & $.16^{*}$ & -.06 & .00 & .04 & $.17^{*}$ & -.14 \\
\hline & -.10 & .03 & ( & -.02 & -.05 & -.02 & -.04 & .06 & .04 & .05 & -.05 & .06 & $-.26^{* * *}$ & .09 & $.15^{*}$ & -.01 & $.20^{* * *}$ & -.05 & .09 & .04 \\
\hline & .01 & .11 & . & .03 & .04 & -.06 & .11 & .00 & $.30^{\dagger}$ & $.22^{* * *}$ & -.05 & $.19^{*}$ & -.08 & -.01 & .04 & .04 & .01 & -.09 & .05 & .09 \\
\hline & .09 & $.14^{*}$ & -.03 & .01 & $.24^{* *}$ & .06 & .01 & $.17^{*}$ & $.14^{*}$ & $.28^{\dagger}$ & -.07 & -.02 & .07 & $.12 *$ & -.09 & .09 & -.07 & -.04 & .00 & .10 \\
\hline Enterprising & $-.17^{*}$ & -.04 & -.01 & -.05 & $.39^{\dagger}$ & .08 & -.05 & $.20^{* * *}$ & -.02 & .04 & $-.19^{*}$ & .08 & -.10 & $-.12^{*}$ & $-.21^{* * *}$ & $-.12 *$ & $.17^{*}$ & .04 & .03 & $.15^{*}$ \\
\hline Conventional & -.05 & $.12^{*}$ & -.05 & .03 & .13 & -.04 & -.06 & .01 & $-.14^{*}$ & -.07 & $-.14^{*}$ & -.07 & -.06 & .01 & $-.22^{* *}$ & -.02 & .02 & .07 & .06 & .11 \\
\hline
\end{tabular}

Note. $N=266$ (full information maximum likelihood). A = correlation between initial latent personality level and initial latent occupation level (i.e., selection effects); $\mathrm{B}_{1}=$ personality trait levels predicting RIASEC occupation changes (i.e., activity effects); $\mathrm{B}_{2}=$ RIASEC occupation levels predicting personality trait changes (i.e., reactivity effects); $\mathrm{C}=$ correlations between changes in traits and changes in occupational characteristics (i.e., correlated change). For correlated change, a positive/negative correlation indicates that both dimensions change in the same/opposite direction. RIASEC $=$ Realistic, Investigative, Artistic, Social, Enterprising, Conventional.

${ }^{\dagger} p<.001 .{ }^{*} p<.05 .{ }^{* * *} p<.01$.

at $\mathrm{T} 1$ predicted subsequent changes in occupational characteristics (i.e., activity effects; Path $\mathrm{B}_{1}$ in Figure 2).

Regarding reactivity effects, the results in Table 3 (columns $\mathrm{B}_{2}$ ) show that starting level occupational characteristics predicted changes in all personality traits, except Extraversion. Contrary to our expectations (Hypothesis 1), only one out of eight reactivity effects was corresponsive with the initial selection effects observed in this study. Specifically, T1 Conventional characteristics were negatively predicted by initial Openness to Experience scores, and these Conventional characteristics also negatively predicted changes in Openness to Experience over time $(\beta=-.14$, $p<.05)$. Seven reactivity effects were observed without corresponding selection effects: Initial Realistic characteristics negatively predicted changes in Neuroticism $(\beta=-.20, p<.01)$ and positively predicted changes in Agreeableness $(\beta=.16, p<.05)$ and Conscientiousness $(\beta=.17, p<.05)$; starting levels of Investigative characteristics were positively associated with changes in Agreeableness $(\beta=.15, p<.05)$, whereas initial Enterprising and Conventional characteristics negatively predicted changes in Agreeableness $(\beta=-.21, p<.01$ and $\beta=-.22, p<$ .01 , respectively). Finally, initial Enterprising characteristics also negatively predicted changes in Openness to Experience $(\beta=-.19, p<.05)$.

In order to facilitate the interpretation of these reactivity effects, personality trait change patterns (based on repeated measures ANOVAs) of T1 low scorers (first quartile) versus T1 high scorers (fourth quartile) were plotted in Figure 3. Panel A illustrates how individuals in initially strong Realistic occupations had stronger decreases in Neuroticism, while at the same time stronger increases in Agreeableness and Conscientiousness over the next 15 years. Further, it can be seen (Panel B) that individuals in initially stronger Investigative occupations demonstrated stronger increases in Agreeableness compared with those in less prominent Investigative occupations at T1. Finally, Figure 3 shows that individuals in initially stronger Enterprising (Panel C) and/or Conventional (Panel D) occupations demonstrated stronger decreases in Openness to Experience and smaller increases in Agreeableness compared with individuals in less prominent Enterprising/Conventional occupations at $\mathrm{T} 1$.

Regarding activity effects, the results in Table 3 (columns $\mathrm{B}_{1}$ ) show that initial personality trait levels predicted future change in all RIASEC occupational characteristics except the Investigative dimension. However, these activity effects generally failed to be corresponsive with the initial selection effects obtained in this study (Hypothesis 2). Specifically, of the nine significant selection effects that were discussed above, only two were also reflected in activity effects: T1 Openness to Experience predicted not only the starting levels of Artistic and Social characteristics but also the changes in these occupational characteristics in the same direction $(\beta=.22, p<.01$; and $\beta=.28$, $p<.001$, respectively). Further, five activity effects were identified without prior selection effects: T1 Neuroticism positively predicted changes in Social $(\beta=.14, p<.05)$ and Conventional $(\beta=.12, p<$ .05) characteristics; T1 Openness to Experience negatively predicted changes in Realistic characteristics $(\beta=-.15, p<.05)$; and Agreeableness positively predicted changes in Social $(\beta=.12, p<.05)$ and negatively predicted changes in Enterprising $(\beta=-.12, p<.05)$ characteristics.

In order to get a sense of what these effects look like, RIASEC change patterns (based on repeated measures ANOVAs) of T1 personality trait low scorers (first quartile) versus T1 personality trait high scorers (fourth quartile) were plotted in Figure 4. Panel A first shows that individuals initially higher on Neuroticism had stronger increases in Social and Conventional occupational characteristics. Further, Figure 4 (Panel B) shows that individuals initially higher on Openness to Experience had stronger decreases in Realistic characteristics, smaller decreases in Artistic characteristics, and stronger increases in Social characteristics. Finally, individuals initially high on Agreeableness had stronger increases in Social and smaller increases in Enterprising characteristics (see Figure 4, Panel C).

Correlated change. Finally, we also examined whether individual differences in trait change were associated with individual differences in RIASEC scale changes (see Path C in Figure 2). As can be seen in Table 3 (columns C), changes in personality traits were associated with simultaneous changes in Artistic, Social, and Enterprising characteristics. Moreover, the comparison of initial selection effects and patterns of correlated change provides some support for the hypothesized corresponsive principle (Hypothesis 3): Four out of nine occupational selection effects were followed by significant correlated change that was moreover in the expected direction. Specifically, T1 Extraversion positively predicted T1 Social and T1 Enter- 

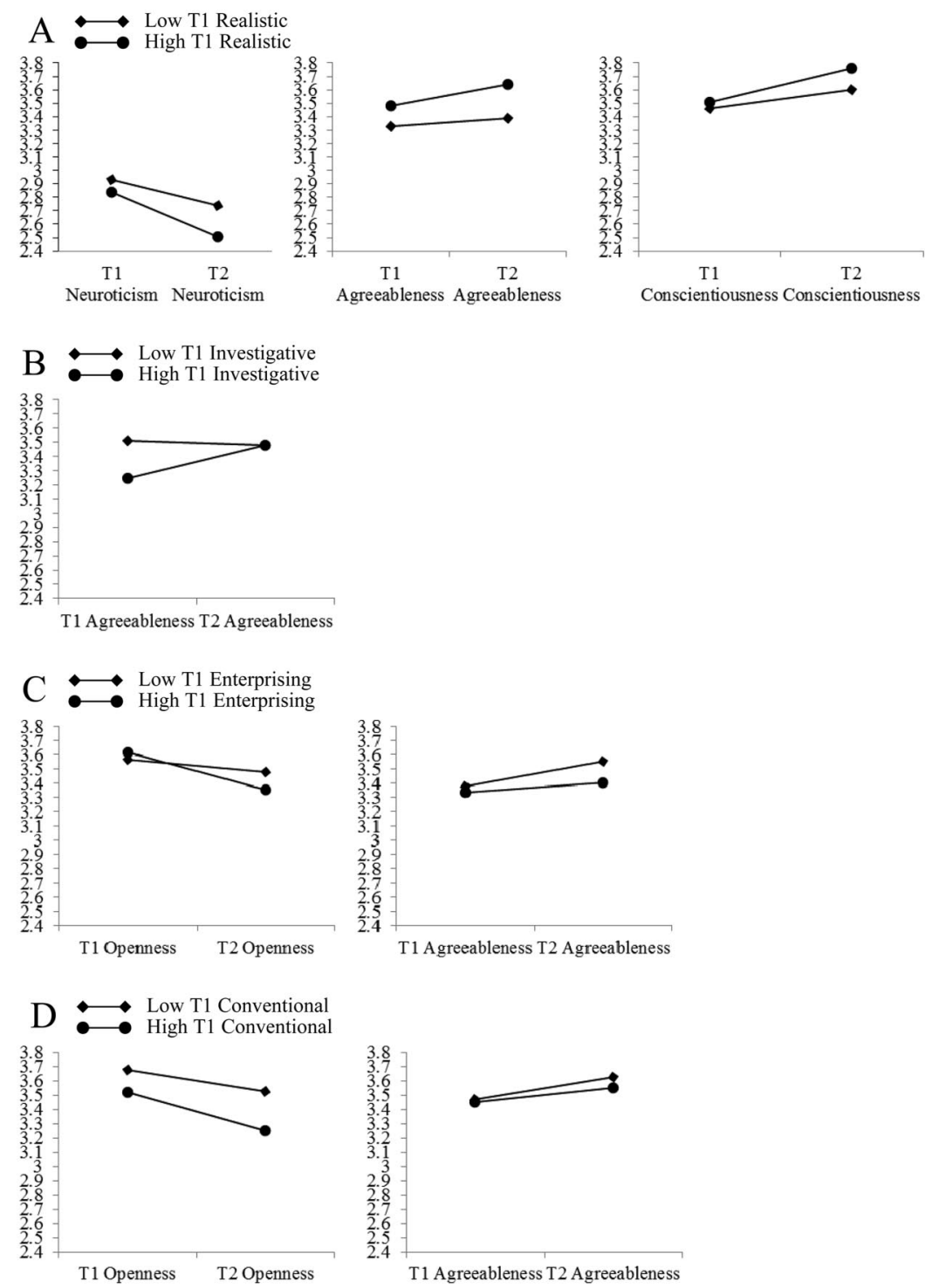

Figure 3. Reactivity effects of T1 Realistic (Panel A), T1 Investigative (Panel B), T1 Enterprising (Panel C), and T1 Conventional (Panel D) vocational characteristics on subsequent change in personality traits. Observed change patterns are reported for first quartile (i.e., low scorers) and fourth quartile (i.e., high scorers) individuals selected from $\mathrm{T} 1$ vocational characteristics distributions. $\mathrm{T} 1=$ Time $1 ; \mathrm{T} 2=$ Time 2 .

prising characteristics, and stronger increases in Extraversion were associated with stronger increases in Social $(r=.17, p<.05)$ and Enterprising $(r=.20, p<.01)$ characteristics over time. T1 Openness to Experience positively predicted $\mathrm{T} 1$ Artistic characteristics, and stronger decreases in Openness to Experience were associated with stronger decreases in Artistic characteristics $(r=.19, p<.05)$. Finally, T1 Conscientiousness positively predicted T1 Enterprising characteristics, and stronger increases in Conscientiousness were associated with stronger increases in Enterprising characteristics over time $(r=.15, p<.05)$. Contrary to our expectations, we also identified one significant correlation between change parameters without prior selection effect: Stronger increases in Enterprising characteristics were associated with smaller increases in Agreeableness over time $(r=-.12, p<.05)$.

\section{Discussion}

In this study, we examined the reciprocal relations between personality traits and occupational characteristics in a longitudinal sample of college alumni. Our general objective was to extend previous research in this area, which exclusively considered the unidirectional effects of personality on occupational characteristics, commonly referred to as selection or gravitation effects (De Fruyt \& Mervielde, 1999; Judge et al., 1999; Woods \& Hampson, 2010). We were specifically interested in the understudied topic of occupational socialization: How do our occupational experiences shape who we are?

For this purpose, we conducted a follow-up of existing research by De Fruyt and Mervielde (1999), now focusing on reciprocity of 

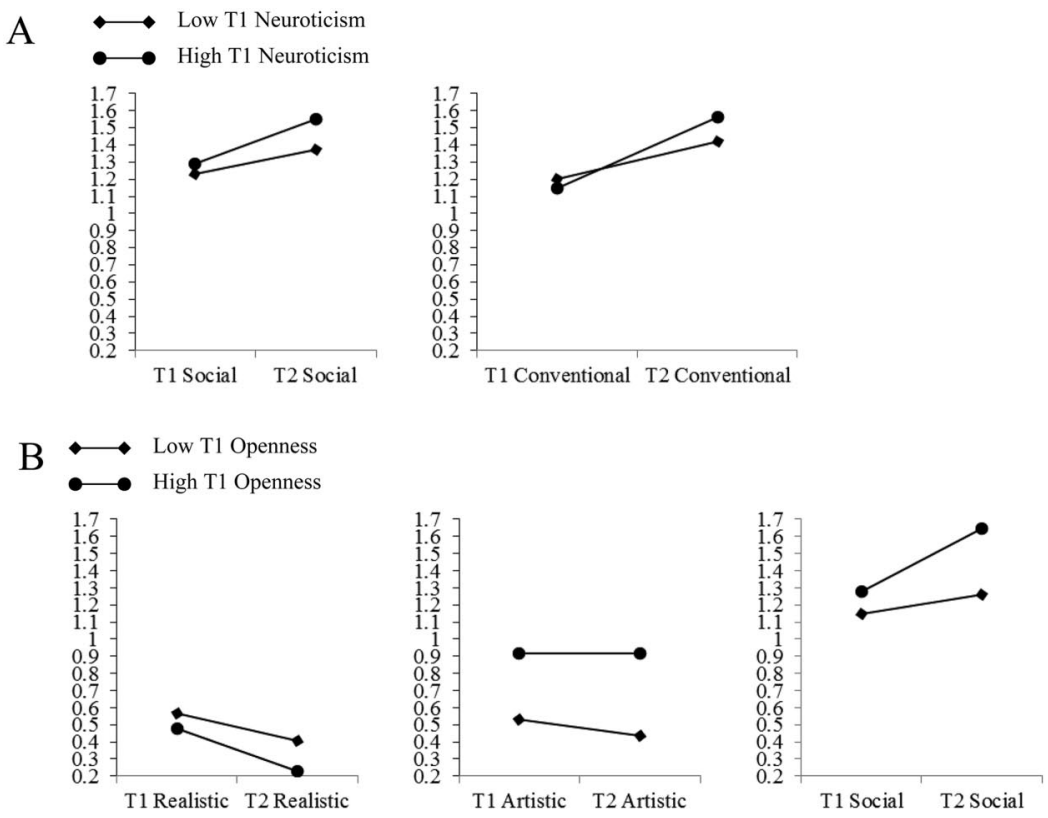

$\mathrm{C} \longrightarrow$ Low T1 Agreeableness
High T1 Agreeableness
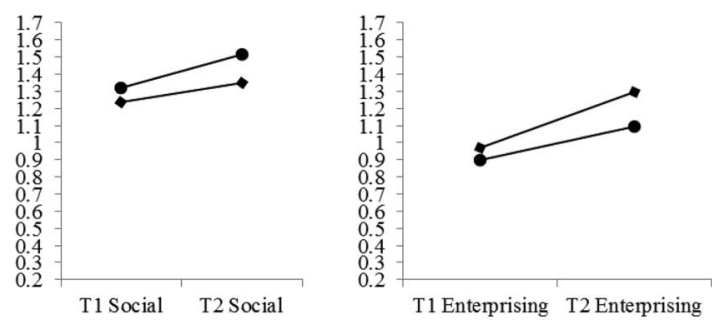

Figure 4. Activity effects of T1 Neuroticism (Panel A), T1 Openness (Panel B), and T1 Agreeableness (Panel C) on subsequent change in vocational characteristics. Observed change patterns are reported for first quartile (i.e., low scorers) and fourth quartile (i.e., high scorers) individuals selected from T1 personality distributions. $\mathrm{T} 1=$ Time $1 ; \mathrm{T} 2=$ Time 2 .

personality and work over time. Given that personality trait change is a process that typically occurs at a modest rate over long periods of time (Roberts \& Wood, 2006), a study design was adopted that covered a substantial and significant period of time, namely, the first 15 years of people's professional careers following graduation from college. Previous research has indicated that these years are particularly important with regard to personality trait change during adulthood. In the professional sphere too, this is a crucial phase in which individuals choose a certain career that can then be further crafted in order to adequately fulfill professional needs. This first period of paid employment has, moreover, been suggested to be the most important in occupational socialization (Frese, 1982).

A distinct oversight in many longitudinal studies of personality trait change is the inclusion of meaningful assessments of situations, contexts, or roles (Roberts \& Wood, 2006). Moreover, inspection of the literature on personality-work interactions in personality psychology typically shows a rather simplistic conception of the work role, often disregarding important differences across various occupational environments in terms of underlying roles or requirements. The recurrent idea in the personality literature is that work role investment, like other forms of social investment such as establishing a family, promotes normative personality trait changes in the direction of greater functional maturity (e.g., increases in Conscientiousness, Emotional Stability, and Agreeableness). By considering the broad spectrum of RIASEC occupational characteristics, we could test our central assumption that the effect of work role investment on personality change depends on specific characteristics of this work role, a key feature of occupational socialization.

Drawing on well-established vocational theory (i.e., Holland's "secondary effects"), and supported by recent findings from the personality literature concerning the corresponsive principle (Caspi, Roberts, \& Shiner, 2005; Roberts et al., 2003), we specifically proposed that occupational selection effects at the beginning of the career would drive subsequent reciprocal relations between personality and work. A reexamination of the selection effects in our restricted longitudinal sample and using multivariate LCMs produced slightly different results compared with the FFMRIASEC correlations that were initially reported (De Fruyt \& 
Mervielde, 1999, p. 715). Some associations now became sufficiently strong to reach the level of statistical significance (e.g., the negative association between Neuroticism and Enterprising characteristics), whereas others now became nonsignificant (e.g., the positive association between Conscientiousness and Conventional characteristics). Several explanations can be put forward for these observed differences. First, it needs to be acknowledged that these selection effects were reexamined in a subsample of the original sample of college alumni. Although our attrition analyses indicated only small differences between both samples in terms of baseline personality and occupational characteristics, this does not rule out that the associations between the variables under consideration can slightly differ in this restricted sample. Also, the absence of mean differences between the original and the restricted sample does not guarantee similar correlation patterns. Second, differences can also be (partially) attributed to the fact that we compare correlations between observed variables with correlations between latent variables. Statistically, the use of latent variable models reduces the biasing effects of measurement error and provides more valid estimates of effects among constructs of interest (Coffman \& MacCallum, 2005).

\section{Reciprocal Relations Between Personality and Work Over Time}

Having reestablished these occupational selection effects, we expected these to (a) set off reactivity effects, whereby traits that got people selected into certain occupational environments are the most likely to change under the influence of these same occupational characteristics in such a way that these traits are deepened (Hypothesis 1), (b) persevere over time into activity effects, whereby individuals selectively deepen those occupational characteristics that were initially selected (Hypothesis 2), and (c) be mirrored in patterns of correlated change (Hypothesis 3). This longitudinal dynamic interplay between traits and work experiences was thus hypothesized to reflect the corresponsive principle of personality development. Although ample evidence was found for each of these three effects, the general pattern clearly was less straightforward than expected, and our hypotheses were only modestly supported.

Before discussing the results regarding the reactivity or socialization effects in greater detail, it is first important to point out that by adopting Holland's RIASEC framework, we focused on occupational socialization, which transcends the level of concrete jobs. Put simply, a job is work for which one receives pay (e.g., teacher at school $X$ ); an occupation is a wide category of jobs with similar characteristics (e.g., educator, physician, or scientist). Although participants might have changed jobs one or more times during this first career stage (see also Wille et al., 2010), our results indicated moderate to strong rank-order stability in occupational characteristics. People scoring higher (lower) on certain occupational characteristics at the beginning of the career also scored higher (lower) on these characteristics 15 years later relative to the same sample of college alumni. This indicates that, for many participants, these initial occupations were not just a "tryout" but were indeed representative for the rest of their career, justifying the examination of the pro- spective effects of initial occupational characteristics on subsequent personality trait change.

Effects of occupational characteristics on personality change. Contrary to our expectations, little evidence for corresponsiveness in reactivity effects was found, as only one of the nine identified selection effects set in motion the hypothesized socialization effect. Individuals higher on Openness to Experience were less likely to select or to be selected into stronger Conventional occupations, and these Conventional characteristics in turn amplified the normative decreases in Openness to Experience. This effect is entirely in line with Holland's suggested secondary effects: People select certain environmental characteristics on the basis of certain personality characteristics and then change under the influence of those same environmental characteristics in a way to further deepen these initial personality traits.

Six additional reactivity effects were also found, however, that had no corresponding selection effect at the career start. These findings indicate that aspects of the work environment can influence changes in personality traits, irrespective of the empirical associations between people's traits and their initial work characteristics. Realistic occupational characteristics predicted stronger increases in Agreeableness and Conscientiousness, and stronger decreases in Neuroticism. Although there were no significant selection effects, these reactivity effects do align with Holland's hypothesized secondary effects for this occupational environment, which include a reinforcement of traits such as conformity, persistence, and stability (Holland, 1997, p. 44). Moreover, it seems that involvement in more Realistic work roles stimulates the normative pattern of personality change that is typically observed during adulthood and that drives individuals toward greater functional maturity.

Interestingly, the reactivity effects associated with Enterprising-Conventional characteristics (i.e., stimulating the normative decrease in Openness to Experience and buffering the normative increase in Agreeableness) uncover a second crucial feature of occupational socialization: Work experiences serve to shape those personality traits that promote effective functioning in a specific occupational context, even if these occupational socialization effects run counter to normative developmental patterns (i.e., the smaller increases in Agreeableness). Enterprising-Conventional occupations (e.g., managerial functions) require a competitive mindset and create an atmosphere of conventional, materialistic attitudes (Holland, 1997). Although not all selection effects were significant, these socialization effects again align with Holland's proposed secondary effects: People in such occupational environments are further encouraged to see themselves as ambitious, domineering, and aggressive, and become less open to new beliefs and practices, leading to a narrow range of interests and a closed belief system (Holland, 1997, pp. 46-48).

One reactivity effect that merits special attention concerns the socialization effect of Investigative characteristics on change in Agreeableness, which was in the opposite direction of what would be expected on the basis of the corresponsive principle. Individuals high on Agreeableness were first less likely to select/be selected into stronger Investigative occupations (negative selection effect). This could be explained by the fact that many of the early career Investigative work environments in the present study were (pre) doctoral research jobs, in which rational, analytical, and radical 
thinking are probably valued higher than compassion, compliance, and interpersonal warmth. Opposite to the corresponsive principle (and to Holland's hypothesized secondary effects), we found individuals in stronger Investigative occupations to demonstrate more pronounced increases in their levels of Agreeableness (positive socialization effect). One potential explanation for this effect could be that many individuals in these early career research jobs are "late bloomers," who eventually "catch up" under the influence of other important sources of social investment responsible for normative trait change. Choosing for a graduate research position in many cases also involves choosing for a prolongation of student life, possibly reflecting a certain level of immaturity, such as reflected in lower levels of Agreeableness. However, under the influence of other social investment processes, such as the establishment of deeply committed romantic relationships, a catch-up in terms of personality trait development toward greater functional maturity could be initiated, as reflected in the greater increases in Agreeableness.

Our expectations regarding the reactivity effects were further disconfirmed because our findings indicated that when selection effects were present, these did not automatically lead to further socialization. For instance, although individuals higher on Extraversion were more likely to start off in jobs with stronger Enterprising characteristics, we did not see Extraversion being reinforced under the influence of these Enterprising characteristics. Before making any strong theoretical inferences, we first considered whether this is merely a statistical/methodological issue. Namely, that through occupational selection processes, there is simply not enough room for change in personality traits. To investigate this possibility, we identified the upper quartile of participants with the highest scores on T1 Enterprising characteristics and inspected the distribution of their T1 Extraversion scores. The mean T1 Extraversion score (on a scale from 1 to 5$)$ of this select sample is $3.62(S D=0.38)$, and scores range between 2.69 and 4.42. Even for these high scorers on Enterprising characteristics, there is still room for change: Scores in the upper quartile of T2 Extraversion scores range between 3.58 and 4.46, with an average of 3.80. That change is possible in the presence of occupational selection is further illustrated by some of our other findings. For example, stronger Conventional work environments were occupied at T1 by people lower on Openness to Experience, and over time Openness to Experience further decreased under the influence of these Conventional characteristics. As we discuss in the Implications for Theory section, we believe that this is not so much a question of "Is there room for change?" but more of "Is there a need for change?"

Effects of personality traits on change in occupational characteristics. Although substantial evidence was found for activity effects, these were, again, generally not in line with our a priori expectations. Specifically, only two out of nine selection effects were also reflected in the activity effects. Openness to Experience was positively associated with initial levels of Artistic and Social characteristics, as well as with changes in both occupational characteristics. In addition, we also identified five activity effects that were unprecedented by significant selection effects. Over time, individuals higher on Neuroticism seek comfort in stronger Social environments where the focus is on cooperation rather than competition, and increasingly seek out the reassuring security and predictability that is characteristic of Conventional environments. Similarly, individuals higher on Agreeableness further craft their careers in a Social direction at the expense of Enterprising characteristics. Finally, we found that individuals higher on Openness to Experience, who are characterized by broad-mindedness, increasingly turn away from occupations with stronger Realistic characteristics, which stimulate inflexible, conforming, and dogmatic thinking (Holland, 1997). Despite the fact that these activity effects did not directly connect with the initial selection effects that were observed in this study, they can, thus, easily be interpreted in a conceptually sound manner. Moreover, these findings illustrate the difference between occupational selection (i.e., the shortterm effect of traits on occupational characteristics) and occupational gravitation (i.e., the long-term effect) and point out activity effects as the missing link between both.

Although activity effects are primarily discussed here as the result of an individual's decision to craft or change occupational environments, it is important to note that such changes in occupational characteristics over the first career half can also be initiated at the employer side. Schneider's (1987) attractionselection-attrition model, for instance, suggests that those who do not fit well will not only self-select out of environments but also be selected out or rejected. From this angle, it is possible that individuals higher on Agreeableness are pushed out of Enterprising environments and into the direction of more Social occupations for which this trait is valued more. Similarly, in more Realistic environments, individuals too high on Openness to Experience may have little chance of surviving because of the potential misfit between personal values or competencies and formal requirements.

Correlated change. Finally, in order to capture the full dynamic of trait-occupation interactions, correlated change was also inspected to investigate codevelopment of personality and work over time in addition to the prospective effects. Although not all selection effects resulted in correlated change, evidence was nonetheless found for corresponsiveness as traits were most likely to change in association with changes in those occupational characteristics that were selected in the first place. Given that the prospective effects in our models provided evidence for activity (traits predicting change in occupational characteristics) as well as for reactivity effects (occupations predicting change in traits), at least these patterns of correlated change indicate that personality and occupations influence each other over time.

\section{Implications for Theory}

Overall, limited evidence was obtained for corresponsiveness between initial selection effects and subsequent reciprocal relations, indicating that reciprocity between personality and work is less straightforward than typically conceptualized. First, reactivity/ socialization effects are possible in the absence of prior selection effects as identified at the very beginning of the career. This does not mean, however, that work experiences impinge themselves on people in a random fashion. We generally found that work environments facilitate the development of traits that are functional for that specific work role, even if this requires change patterns that run counter to normative developmental tendencies. Second, occupational selection effects at the career start do not automatically 
lead to reactivity. The basic idea of the corresponsive principle and Holland's secondary effects is that people select certain environments on the basis of their personality profiles and then change under the influence of those same environments in a way to further deepen these initial personality traits. One of the lessons to be learned is that by focusing on change, we underestimate the influence that environmental characteristics have on personality traits. The single most important characteristic of personality development in adulthood is trait stability and environmental characteristics play a crucial role herein.

The key issue here is the concept of fit. Imagine someone relatively high on Extraversion who selected or was selected in a work environment with a relatively strong Enterprising component. Imagine that for this person, there is an optimal balance between his or her personal competencies and aspirations and the job-level requirements. Should this person benefit from having substantial increases in Extraversion? In other words: Is there a need for change? Intuitively, the answer is no, and recent insights from the personality-performance literature substantiate this proposition. Specifically, research has demonstrated that there seem to be optimal levels of a certain trait and that people may also have "too much of a good thing"(e.g., Le et al., 2011). There is one recent study that illustrates this nicely for Extraversion and Enterprising characteristics. Specifically, Grant (2013) demonstrated that "ambiverts," that is, those scoring in the middle of the introversion-extraversion continuum, perform the best in terms of sales revenue. Clearly, there are limits to where higher levels of Extraversion or increases in Extraversion are beneficial.

What our findings illustrate is that this corresponsive principle and the suggested secondary effects (a) overemphasize change and (b) are not sensible enough to account for aspects of fit. They overemphasize change because both occupational and personal characteristics show remarkable signs of stability across time. Fit can be thought of as a kind of optimal balance between certain environmental features and certain personal characteristics, and further change may disturb this balance. Although our study did provide evidence for reciprocity between work and occupation, we believe that these effects underestimate the true impact of personality on occupational characteristics, and vice versa. The effect of personality traits on our work environment also consists of consolidating certain occupational characteristics that are preferred. Likewise, work environments also influence personality development by stabilizing traits that facilitate workplace functioning. The idea here is that if a person is selected into an environment that fits well, then there is probably less press for change. Theory on reciprocal relations between personality and work should take this into account.

From a broader perspective, one of the main theoretical contributions of this study entails the installation of a new model of personality psychology into the literature. The traditional conceptualization of traits as predictor variables that are essentially fixed has greatly served applied psychologists in their focus on validity aspects of personality for various organizational and career outcomes. However, to date this version of personality psychology adopted in the I/O literature proves to be overly static. Trait models that do not incorporate the transactions between personality and situation over time fail to account for conceptual or empirical findings of personality development (Fraley \& Roberts, 2005).
Personality psychology has now convincingly demonstrated that traits continue to change in adulthood and that life experiences play a role therein (Hudson et al., 2012; Jackson, Thoemmes, Jonkmann, Luedtke, \& Trautwein, 2012; Lodi-Smith \& Roberts, 2007; Roberts et al., 2003). By showing in this study that work environments can significantly influence patterns of FFM trait change through processes of occupational socialization, we further substantiated this call for a revised conceptualization of personality in which traits and work experiences are in constant transaction. Moreover, we clarified the basic mechanisms (e.g., state-trait interactions) describing how occupational experiences may shape who we are.

We believe that this reconceptualization of personality in the $\mathrm{I} / \mathrm{O}$ literature also holds important implications for well-established theories on workplace functioning. Trait activation theory (TAT; Tett \& Burnett, 2003), for instance, is now widely accepted as a person-situation interactionist model of job performance that specifies the conditions under which particular personality traits will predict effective functioning in particular jobs. In light of the present study, a reformulation of TAT would allow for a more complete understanding of personality functioning at work. Specifically, what seems to be missing in this model is a bidirectional association between personality and work behavior, whereby repeated activation of certain traits that are favorably evaluated in certain work environments (i.e., the amalgam of task-level, sociallevel, and organization-level work demands) could, over time, result in a further development of these traits.

Finally, in addition to bringing some recent advances regarding trait development from the personality literature to I/O psychology, our study also informs personality psychologists how to refine their theory on personality change. Our findings indeed support the assumption that investment in the work role may serve to further develop those traits that are accommodating for effective functioning at work (Hudson et al., 2012), but at the same time illustrate that this effect of work role investment on personality development depends on the specific characteristics or requirements in that work environment. This further means that in some work environments (e.g., stronger Enterprising environments), the effect of occupational socialization may be to stimulate normative changes in certain traits (e.g., stronger decreases in Openness to Experience), while at the same time buffering other normative changes (e.g., smaller increases in Agreeableness). We would like to compare these findings with those recently reported by Jackson and colleagues (2012), who found a similar long-lasting influence of military experience on personality trait change. Compared with a control group, military recruits had lower levels of Agreeableness after training, and these levels persisted 5 years after training, even after participants entered college or the labor market. Although we do not want to equate Enterprising occupations with military training, a joint consideration of these effects is insightful because it indicates that the effect of life experiences on trait change depends on the specific characteristics of that experience. It can be concluded that a more complete understanding of occupational socialization requires a refinement of the social investment perspective on personality development in such ways that differences between work environments, for example, in terms of Holland's framework, can no longer be ignored. 


\section{Practical Implications}

For more than half a century now, Holland's RIASEC theory of vocational personalities and work environments has had a tremendous impact in applied areas of vocational and counseling psychology (Nauta, 2010). Our central finding that personality not only predicts, but is also predicted by (change in) occupational characteristics sheds a new light on this theory and its applications. Typically in vocational guidance settings, personality (or related constructs such as interests) is assessed by the counselor in order to gain insight into the underlying motivations and/or preferences of clients. This information is subsequently used to guide people through the processes of selecting the right environments (at the beginning of a professional or educational career) or reorienting a career. Acknowledging reverse (i.e., occupational socialization) effects, however, opens the door for an additional set of valuable interventions, whereby personality and work environments should be treated as interactional rather than seeing traits as fixed and jobs as fitting to them. First, this information is helpful for counselors in order to understand certain changes in clients, which they often cannot adequately pinpoint themselves. Consider, for instance, the tough manager who, at a certain point in his or her career, experiences increasing difficulties in adequately combining the competitiveness of a strong Enterprising work role with the need for compassion in other (e.g., romantic) life roles. It may be very insightful for such people to know about these occupational socialization effects, to identify those work role demands that trigger these effects, and to learn how to adequately separate effective ways of functioning in different life domains.

From a broader perspective, findings regarding the changeability of basic personality traits are important for applied psychologists given the centrality of personality assessment in different organizational settings, including personnel selection, coaching, and development. Combined with recent findings reported by $\mathrm{Wu}$ and Griffin (2012) regarding the malleability of trait core selfevaluations, our results are particularly informative for applied psychologists interested in targeted personality change. To give one example, personality trait assessments are frequently used in coaching and development (De Fruyt et al., 2009; De Fruyt, Wille, \& Furnham, in press). The utility of using such assessments is usually framed as helping people to understand both personal strengths and areas of inconsistency between traits and work requirements. The thorny issue of change is usually approached by proposing behavioral change, thereby sidestepping the question about personality change because traits are assumed to be stable over time. If there are real developmental influences on traits from work experiences, then it may logically follow that people can, if they wish, change aspects of their personality on the basis of exposure to new kinds of activity and environments, reinforcement, and practice. Such change may be more than simple behavior change, but rather influence sense of identity at its core, and perceptions of one's own traits. Of course, more research is needed to support these assertions.

\section{Limitations and Future Research}

In addition to these theoretical and applied implications, the limitations of this study should be noted. First, personality and occupational characteristics were measured on only two occasions; thus, our longitudinal analyses were limited in several ways. One consequence is that our LCMs could only estimate linear change patterns, whereas previous research has indicated that changes in traits (e.g., Hopwood, Donnellan, Blonigen, \& Krueger, 2011) as well as occupational characteristics (e.g., Wille et al., 2012) may also follow nonlinear trajectories. In addition, with only two measurement occasions, the investigation of bidirectionality is limited, as only the prospective effects of personality levels on subsequent changes in occupational characteristics, and vice versa, can be examined. In designs with more than two assessment points, the direction of effects can be tested more elaborately by testing alternative cross-lagged models that incorporate more than one change factor for each variable (Ferrer \& McArdle, 2003, 2010).

Second, all study variables were assessed using self-reports only, which may have introduced common method bias. However, it was pointed out to us by an anonymous reviewer that if common method was a severe concern in the present article, then we would expect to see elevated and statistically significant correlations among variables measured using the common method, especially for those variables measured at the same time point. This was not the case. For example, the T1 correlations among personality traits reveal a number of nonsignificant correlations, and even the within-time, cross-construct correlations between personality and RIASEC ratings also demonstrated nonsignificant correlations.

Third, and related, it could be argued that the perceptions of occupational characteristics were partially biased by people's personal dispositions (e.g., Judge, Bono, \& Locke, 2000). In this regard, it was interesting to see that, at least for a subsample of the respondents, the PCI self-reports converged relatively well with objective RIASEC ratings that were extracted from the O*NET database. Moreover, unreported post hoc analyses also indicated that the test-retest correlations of self-reported occupational characteristics were highly comparable to those of the objective O*NET ratings, indicating that the rank-order stability of occupational characteristics cannot be attributed to a third variable (i.e., personality) driving response biases at both time points. The major advantage of using self-report PCI ratings is that these can reflect the particularities of specific work environments. For instance, the job of Logistics Manager in company X may be slightly different from the same job in company $\mathrm{Y}$, and even within the same company, a junior Logistics Manager will probably have different responsibilities compared with a more senior Logistics Manager. These differences are not adequately represented in generic $\mathrm{O}^{*}$ NET ratings, although they are clearly of great importance for research examining the impact of work environments on personality development.

Lastly, when interpreting this study's findings, it is important to keep in mind that these are based on a selected sample of 266 college alumni that could be tracked over 15 years. Clearly, this is a unique sample, and caution is warranted regarding the generalizability of our findings. For example, mean differences were observed in baseline personality traits (Extraversion and Openness to Experience) and initial (Social) occupational characteristics between this selected sample and the starting college alumni sample. Although these differences were limited, small in magnitude, and did not seem to influence the intercorrelations between T1 study variables, they may have affected other parameters such as the longitudinal change patterns in these traits and characteristics. Aside from these attrition effects, caution is also warranted because the research questions were examined in a selected sample 
of college alumni only, which means that all participants were highly educated. It remains an open question whether similar reciprocal effects between personality and occupational characteristics can be identified in people with more diverse educational levels.

Alongside these study limitations, a number of directions for future research can also be delineated. First, regarding activity effects, it is important to point out that the changes in RIASEC characteristics observed in the present study could reflect changes in a given job environment (e.g., through job crafting) as well as result from one changing his or her job environment for another. Although both processes fall under the umbrella of "activity," noting this distinction here is important, as future research may be able to look at the two types of activity separately.

Second, the general finding that the association between personality and work is bidirectional rather than unidirectional should be further examined against a broader range of work-related criteria. For instance, there is now a large body of evidence supporting the validity of traits to predict work-family conflict (Allen et al., 2012) and burnout (Swider \& Zimmerman, 2010). Given the significance of these outcomes for an individual's personal wellbeing, one could expect such work experiences to also shape people's personality over time.

Third, more research is needed that addresses personalityenvironment transactions at a microlevel. Specifically, future research should explicitly test the processes described by the sociogenomic model of personality by actually assessing personality states and their interactions with environmental characteristics, for instance, using experience-sampling methodologies.

Fourth, we adopted a strong variable-centered approach in our study, examining the reciprocal effects of Big Five personality dimensions and RIASEC vocation dimensions. Of course, every job is always a combination of at least the six RIASEC occupational characteristics. It could be, for instance, that a specific job combines certain occupational characteristics that may have differential effects on patterns of personality development. Specifically, our study demonstrated that Realistic and Investigative occupational characteristics stimulated increases in Agreeableness, whereas Enterprising and Conventional characteristics had a mitigating effect. What happens in concrete jobs where, for instance, Enterprising and Realistic characteristics are combined?

Finally, research on the reciprocity between personality and work characteristics should further examine the role that fit or congruence plays in these processes. For example, Roberts and Robins (2004) showed that students that fit better with the value system of their college or university demonstrated less personality change over time. Research is needed that addresses this issue in the work context and that combines aspects of corresponsiveness with person-environment congruence. Specifically, we need more longitudinal designs in which the evolution of personenvironment fit is tracked across wider career stages and using state-of-the-art methodology. This would require comprehensive and commensurate assessments of personal (e.g., RIASEC occupational interests) and environmental (e.g., RIASEC occupational characteristics) features, as well as the application of sophisticated quantitative techniques (e.g., angular agreement) to compute congruence levels over time. Our findings carefully suggest that there is a large group of people who finish their college education and enter into their chosen occupational area, but there is also an equally large subset of people who do not. Future research that can establish what is different about these two groups of people could also be of great value to career counselors.

\section{Conclusions}

For many people, occupations are one of the defining features of adult life and, hence, a significant source of identity. The absence of a literature on how work affects personality development may represent one of the biggest oversights in the field. This lack of research has a double origin: (a) scarce longitudinal research designs and (b) inappropriate theory of personality as essentially fixed trait predictors. In the present study, we addressed this gap in the literature by testing the longitudinal and reciprocal relations between personality and occupational characteristics in a college alumni sample that was tracked over 15 years. Recent advancements in the personality literature were used to develop an appropriate theoretical framework that allows for bidirectional effects. Our findings illustrate that personality predicts and is predicted by work environments, so to purport that the direction of influence from personality to work is only one way seems no longer valid. We believe that as empirical evidence regarding occupational socialization effects will start to accumulate, further integration and refinement of various theoretical perspectives (e.g., theory of work adjustment, social investment, sociogenic theory, Holland's secondary effects, TAT) will be possible, allowing a better understanding of how work influences personality, in addition to the more commonly studied trait validity effects.

\section{References}

Allemand, M., Zimprich, D., \& Hertzog, C. (2007). Cross-sectional age differences and longitudinal age changes of personality in middle adulthood and old age. Journal of Personality, 75, 323-358. doi:10.1111/j .1467-6494.2006.00441.x

Allen, T. D., Johnson, R. C., Saboe, K. N., Cho, E., Dumani, S., \& Evans, S. (2012). Dispositional variables and work-family conflict: A metaanalysis. Journal of Vocational Behavior, 80, 17-26. doi:10.1016/j.jvb .2011 .04 .004

Barrick, M. R., Mount, M. K., \& Gupta, R. (2003). Meta-analysis of the relationship between the five-factor model of personality and Holland's occupational types. Personnel Psychology, 56, 45-74. doi:10.1111/j .1744-6570.2003.tb00143.x

Bell, N. E., \& Staw, B. M. (1989). People as sculptors versus sculpture: The roles of personality and personal control in organizations. In M. B. Arthur, D. T. Hall, \& B. S. Lawrence (Eds.), Handbook of career theory (pp. 232-251). New York, NY: Cambridge University Press. doi: 10.1017/CBO9780511625459.014

Betz, N. E., Borgen, F. H., \& Harmon, L. W. (2006). Vocational confidence and personality in the prediction of occupational group membership. Journal of Career Assessment, 14, 36-55. doi:10.1177/ 1069072705282434

Bleidorn, W. (2012). Hitting the road to adulthood: Short-term personality development during a major life transition. Personality and Social Psychology Bulletin, 38, 1594-1608. doi:10.1177/0146167212456707

Boudreau, J. W., \& Boswell, W. R. (2001). Effects of personality on executive career success in the United States and Europe. Journal of Vocational Behavior, 58, 53-81. doi:10.1006/jvbe.2000.1755

Browne, M. W., \& Cudeck, R. (1993). Alternative ways of assessing model fit. In K. A. Bollen \& J. S. Long (Eds.), Testing structural equation models (pp. 136-162). Newbury Park, CA: Sage.

Caspi, A., \& Bem, D. J. (1990). Personality continuity and change across 
the life course. In L. A. Pervin (Ed.), Handbook of personality: Theory and research (pp. 549-575). New York, NY: Guilford Press.

Caspi, A., Roberts, B. W., \& Shiner, R. L. (2005). Personality development: Stability and change. Annual Review of Psychology, 56, 453-484. doi:10.1146/annurev.psych.55.090902.141913

Coffman, D. L., \& MacCallum, R. C. (2005). Using parcels to convert path analysis models into latent variable models. Multivariate Behavioral Research, 40, 235-259. doi:10.1207/s15327906mbr4002_4

Costa, P. T., \& McCrae, R. R. (1992). NEO-PI-R professional manual. Odessa, FL: Psychological Assesment Resources.

Dawis, R. V., \& Lofquist, L. H. (1984). A psychological theory of work adjustment: And individual-differences model and its applications. Minneapolis: University of Minnesota Press.

De Fruyt, F. (2002). A person-centered approach to P-E fit questions using a multiple-trait model. Journal of Vocational Behavior, 60, 73-90. doi:10.1006/jvbe.2001.1816

De Fruyt, F., De Clercq, B. J., Miller, J., Rolland, J. P., Jung, S. C., Taris, R., . . V Van Hiel, A. (2009). Assessing personality at risk in personnel selection and development. European Journal of Personality, 23, 51-69. doi:10.1002/per.703

De Fruyt, F., \& Mervielde, I. (1999). RIASEC types and Big Five traits as predictors of employment status and nature of employment. Personnel Psychology, 52, 701-727. doi:10.1111/j.1744-6570.1999.tb00177.x

De Fruyt, F., Wille, B., \& Furnham, A. (in press). Assessing aberrant personality in managerial coaching: Measurement issues and prevalence rates across employment sectors. European Journal of Personality. doi:10.1002/per.1911

Donohue, R. (2006). Person-environment congruence in relation to career change and career persistence. Journal of Vocational Behavior, 68, 504-515. doi:10.1016/j.jvb.2005.11.002

Ferrer, E., \& McArdle, J. J. (2003). Alternative structural models for multivariate longitudinal data analysis. Structural Equation Modeling: A Multidisciplinary Journal, 10, 493-524. doi:10.1207/ S15328007SEM1004_1

Ferrer, E., \& McArdle, J. J. (2010). Longitudinal modeling of developmental changes in psychological research. Current Directions in Psychological Science, 19, 149-154. doi:10.1177/0963721410370300

Fleeson, W., \& Jolley, S. (2006). A proposed theory of the adult development of intraindividual variability in trait-manifesting behavior. In D. Mroczek \& T. D. Little (Eds.), Handbook of personality development (pp. 41-59). Mahwah, NJ: Erlbaum.

Fraley, R. C., \& Roberts, B. W. (2005). Patterns of continuity: A dynamic model for conceptualizing the stability of individual differences in psychological constructs across the life course. Psychological Review, 112, 60-74. doi:10.1037/0033-295X.112.1.60

Frese, M. (1982). Occupational socialization and psychological development: An underemphasized research perspective in industrial psychology. Journal of Occupational Psychology, 55, 209-224. doi:10.1111/j .2044-8325.1982.tb00095.x

Gottfredson, G. D., \& Holland, J. L. (1991). The Position Classification Inventory. Odessa, FL: Psychological Assessment Resources.

Gottfredson, G. D., Jones, E. M., \& Holland, J. L. (1993). Personality and vocational interests: The relation of Holland's six interest dimensions to five robust dimensions of personality. Journal of Counseling Psychology, 40, 518-524. doi:10.1037/0022-0167.40.4.518

Grant, A. M. (2013). Rethinking the extraverted sales ideal: The ambivert advantage. Psychological Science, 24, 1024-1030. doi:10.1177/ 0956797612463706

Hertzog, C., \& Nesselroade, J. R. (2003). Assessing psychological change in adulthood: An overview of methodological issues. Psychology and Aging, 18, 639-657. doi:10.1037/0882-7974.18.4.639

Hoekstra, H. A., Ormel, J., \& De Fruyt, F. (1996). NEO Persoonlijkheidsvragenlijsten NEO-PI-R en NEO-FFI. Handleiding [NEO Personality
Inventories: NEO-PI-R and NEO-FFI manual.]. Lisse, Switzerland: Swets \& Zeitlinger.

Hogerheijde, R. P., Van Amstel, B., De Fruyt, F., \& Mervielde, I. (1995). Het Functie- en Omgevingstyperingsonderzoek - Nederlands/Vlaamse editie. [The Dutch/Flemish adaptation of the Position Classification Inventory]. Lisse, Switzerland: Swets \& Zeitlinger.

Holland, J. L. (1958). A personality inventory employing occupational titles. Journal of Applied Psychology, 42, 336-342. doi:10.1037/ h0047330

Holland, J. L. (1985). Making vocational choices: A theory of vocational personalities and work environments (2nd ed.). Odessa, FL: Psychological Assessment Resources.

Holland, J. L. (1996). Exploring careers with a typology: What we have learned and some new directions. American Psychologist, 51, 397-406. doi:10.1037/0003-066X.51.4.397

Holland, J. L. (1997). Making vocational choices: A theory of vocational personalities and work environments (3rd ed.). Odessa, FL: Psychological Assessment Resources.

Hopwood, C. J., Donnellan, M. B., Blonigen, D. M., \& Krueger, R. F. (2011). Genetic and environmental influences on personality trait stability and growth during the transition to adulthood: A three-wave longitudinal study. Journal of Personality and Social Psychology, 100, 545-556. doi:10.1037/a0022409

Howell, D. C. (2007). The treatment of missing data. In W. Outhwaite \& S. P. Turner (Eds.), The SAGE handbook of social science methodology (pp. 208-224). Thousand Oaks, CA: Sage. doi:10.4135/9781848607958 .n11

Hox, J. J. (2000). Multilevel analyses of groups and longitudinal data. In D. Todd, K. U. Schnabel, \& J. Baumert (Eds.), Modeling longitudinal and multilevel data: Practical issues, applied approaches, and specific examples (pp. 15-32). Mahwah, NJ: Erlbaum.

Hudson, N. W., Roberts, B. W., \& Lodi-Smith, J. (2012). Personality trait development and social investment in work. Journal of Research in Personality, 46, 334-344. doi:10.1016/j.jrp.2012.03.002

Jackson, J. J., Bogg, T., Walton, K. E., Wood, D., Harms, P. D., LodiSmith, J., . . Roberts, B. W. (2009). Not all conscientiousness scales change alike: A multimethod, multisample study of age differences in the facets of conscientiousness. Journal of Personality and Social Psychology, 96, 446-459. doi:10.1037/a0014156

Jackson, J. J., Thoemmes, F., Jonkmann, K., Luedtke, O., \& Trautwein, U. (2012). Military training and personality trait development: Does the military make the man, or does the man make the military? Psycholog ical Science, 23, 270-277. doi:10.1177/0956797611423545

Jöreskog, K. G., \& Sörbom, D. (2004). LISREL 8.7 for Windows [Computer software]. Lincolnwood, IL: Scientific Software International.

Judge, T. A., Bono, J. E., \& Locke, E. A. (2000). Personality and job satisfaction: The mediating role of job characteristics. Journal of Applied Psychology, 85, 237-249. doi:10.1037/0021-9010.85.2.237

Judge, T. A., Higgins, C. A., Thoresen, C. J., \& Barrick, M. R. (1999). The Big Five personality traits, general mental ability, and career success across the life span. Personnel Psychology, 52, 621-652. doi:10.1111/ j.1744-6570.1999.tb00174.x

Judge, T. A., Klinger, R., Simon, L. S., \& Yang, I. W. F. (2008). The contributions of personality to organizational behavior and psychology: Findings, criticisms, and future research directions. Social and Personality Psychology Compass, 2, 1982-2000. doi:10.1111/j.1751-9004 2008.00136.x

Le, H., Oh, I.-S., Robbins, S. B., Ilies, R., Holland, E., \& Westrick, P. (2011). Too much of a good thing: Curvilinear relationships between personality traits and job performance. Journal of Applied Psychology, 96, 113-133.

Little, R. J. A. (1988). A test of missing completely at random for multivariate data with missing values. Journal of the American Statis- 
tical Association, 83, 1198-1202. doi:10.1080/01621459.1988 .10478722

Little, T. D., Cunningham, W. A., Shahar, G., \& Widaman, K. F. (2002). To parcel or not to parcel: Exploring the question, weighing the merits. Structural Equation Modeling: A Multidisciplinary Journal, 9, 151-173.

Lodi-Smith, J., \& Roberts, B. W. (2007). Social investment and personality: A meta-analysis of the relationship of personality traits to investment in work, family, religion, and volunteerism. Personality and Social Psychology Review, 11, 68-86. doi:10.1177/1088868306294590

McArdle, J. J. (1980). Causal modeling applied to psychonomic systems simulation. Behavior Research Methods \& Instrumentation, 12, 193209. doi:10.3758/BF03201598

McArdle, J. J., \& Nesselroade, J. R. (1994). Using multivariate data to structure developmental changes. In S. H. Cohen \& H. W. Reese (Eds.), Life-span developmental psychology: Methodological contributions (pp. 223-267). Hillsdale, NJ: Erlbaum.

McCrae, R. R., \& Costa, P. T. (1987). Validation of the five-factor model of personality across instruments and observers. Journal of Personality and Social Psychology, 52, 81-90. doi:10.1037/0022-3514.52.1.81

McCrae, R. R., \& Costa, P. T. (2003). Personality in adulthood: A five-factor theory perspective (2nd ed.). New York, NY: Guilford Press. doi: $10.4324 / 9780203428412$

McCrae, R. R., \& Terracciano, A. (2005). Universal features of personality traits from the observer's perspective: Data from 50 cultures. Journal of Personality and Social Psychology, 88, 547-561. doi:10.1037/00223514.88.3.547

Mount, M. K., Barrick, M. R., \& Stewart, G. L. (1998). Five-factor model of personality and performance in jobs involving interpersonal interactions. Human Performance, 11, 145-165.

Nauta, M. M. (2010). The development, evolution, and status of Holland's theory of vocational personalities: Reflections and future directions for counseling psychology. Journal of Counseling Psychology, 57, 11-22. doi: $10.1037 / \mathrm{a} 0018213$

Neyer, F. J., \& Lehnart, J. (2007). Relationships matter in personality development: Evidence from an 8-year longitudinal study across young adulthood. Journal of Personality, 75, 535-568. doi:10.1111/j.14676494.2007.00448.x

Oleski, D., \& Subich, L. M. (1996). Congruence and career change in employed adults. Journal of Vocational Behavior, 49, 221-229. doi: 10.1006/jvbe.1996.0041

O*NET Resource Center. (2012). The O*NET 17.0 analyst database. Available at http://www.onetcenter.org/db_releases.html

Penney, L. M., David, E., \& Witt, L. A. (2011). A review of personality and performance: Identifying boundaries, contingencies, and future research directions. Human Resource Management Review, 21, 297-310. doi:10.1016/j.hrmr.2010.10.005

Roberts, B. W. (2006). Personality development and organizational behavior. Research in Organizational Behavior, 27, 1-40. doi:10.1016/ S0191-3085(06)27001-1

Roberts, B. W. (2007). Contextualizing personality psychology. Journal of Personality, 75, 1071-1082. doi:10.1111/j.1467-6494.2007.00467.x

Roberts, B. W. (2009). Back to the future: Personality and assessment and personality development. Journal of Research in Personality, 43, 137145. doi:10.1016/j.jrp.2008.12.015

Roberts, B. W., Caspi, A., \& Moffitt, T. E. (2003). Work experiences and personality development in young adulthood. Journal of Personality and Social Psychology, 84, 582-593. doi:10.1037/0022-3514.84.3.582

Roberts, B. W., \& DelVecchio, W. F. (2000). The rank-order consistency of personality traits from childhood to old age: A quantitative review of longitudinal studies. Psychological Bulletin, 126, 3-25. doi:10.1037/ 0033-2909.126.1.3

Roberts, B. W., \& Jackson, J. J. (2008). Sociogenomic personality psychology. Journal of Personality, 76, 1523-1544. doi:10.1111/j.14676494.2008.00530.x
Roberts, B. W., \& Robins, R. W. (2004). Person-environment fit and its implications for personality development: A longitudinal study. Journal of Personality, 72, 89-110. doi:10.1111/j.0022-3506.2004.00257.x

Roberts, B. W., Robins, R. W., Caspi, A., \& Trzesniewski, K. H. (2003). Personality trait development in adulthood. In J. Mortimer \& M. Shanahan (Eds.), Handbook of the life course (pp. 579-595). New York, NY: Plenum Press. doi:10.1007/978-0-306-48247-2_26

Roberts, B. W., Walton, K. E., \& Viechtbauer, W. (2006). Patterns of mean-level change in personality traits across the life course: A metaanalysis of longitudinal studies. Psychological Bulletin, 132, 1-25. doi: 10.1037/0033-2909.132.1.1

Roberts, B. W., \& Wood, D. (2006). Personality development in the context of the neo-socioanalytic model of personality. In D. K. Mroczek $\&$ T. D. Little (Eds.), Handbook of personality development (pp. 11-39). Mahwah, NJ: Erlbaum.

Roberts, B. W., Wood, D., \& Caspi, A. (2008). The development of personality traits in adulthood. In O. P. John, R. W. Robins, \& L. A. Pervin (Eds.), Handbook of personality: Theory and research (Vol. 3, pp. 375-398). New York, NY: Guilford Press.

Roberts, B. W., Wood, D., \& Smith, J. L. (2005). Evaluating five factor theory and social investment perspectives on personality trait development. Journal of Research in Personality, 39, 166-184. doi:10.1016/j .jrp.2004.08.002

Robins, R. W., Noftle, E. E., Trzesniewski, K. H., \& Roberts, B. W. (2005). Do people know how their personality has changed? Correlates of perceived and actual personality change in young adulthood. Journal of Personality, 73, 489-522. doi:10.1111/j.1467-6494.2005.00317.x

Scarr, S., \& McCartney, K. (1983). How people make their own environments: A theory of genotype-environment effects. Child Development, $54,424-435$.

Schafer, J. L. (1997). Analysis of incomplete multivariate data. London, England: Chapman \& Hall. doi:10.1201/9781439821862

Schafer, J. L., \& Graham, J. W. (2002). Missing data: Our view of the state of the art. Psychological Methods, 7, 147-177. doi:10.1037/1082-989X 7.2.147

Schneider, B. (1987). The people make the place. Personnel Psychology, 40, 437-453. doi:10.1111/j.1744-6570.1987.tb00609.x

Scollon, C. N., \& Diener, E. (2006). Love, work, and changes in extraversion and neuroticism over time. Journal of Personality and Social Psychology, 91, 1152-1165. doi:10.1037/0022-3514.91.6.1152

Sliwinski, M. J., Hofer, S. M., \& Hall, C. (2003). Correlated and coupled cognitive change in older adults with and without preclinical dementia Psychology and Aging, 18, 672-683. doi:10.1037/0882-7974.18.4.672

Snyder, M., \& Ickes, W. (1985). Personality and social behavior. In E Aronson \& G. Lindzey (Eds.), Handbook of social psychology (pp. 883-947). New York, NY: Random House.

Sutin, A. R., \& Costa, P. T. (2010). Reciprocal influences of personality and job characteristics across middle adulthood. Journal of Personality, 78, 257-288. doi:10.1111/j.1467-6494.2009.00615.x

Swider, B. W., \& Zimmerman, R. D. (2010). Born to burnout: A metaanalytic path model of personality, job burnout, and work outcomes. Journal of Vocational Behavior, 76, 487-506. doi:10.1016/j.jvb.2010.01 .003

Tett, R. P., \& Burnett, D. D. (2003). A personality trait-based interactionist model of job performance. Journal of Applied Psychology, 88, 500-517. doi:10.1037/0021-9010.88.3.500

Van Maanen, J. (1976). Breaking in: Socialization to work. In R. Dubin (Ed.), Handbook of work organization and society (pp. 67-130). Chicago, IL: Rand McNally.

Volpert, W. (1975). Die Lohnarbeitswissenschaft und die Psychologie der Arbeitstätigkeit [Wage labor science and the psychology of work activity]. In P. Groskurt \& W. Volpert (Eds.), Lohnarbeitpsychologie (pp. 11-196). Frankfurt, Germany: Fischer. 
Wille, B., Beyers, W., \& De Fruyt, F. (2012). A transactional approach to person-environment fit: Reciprocal relations between personality development and career role growth across young to middle adulthood. Journal of Vocational Behavior, 81, 307-321. doi:10.1016/j.jvb.2012.06 .004

Wille, B., De Fruyt, F., \& De Clercq, B. (2013). Expanding and reconceptualizing aberrant personality at work: Validity of five-factor model aberrant personality tendencies to predict career outcomes. Personnel Psychology, 66, 173-223. doi:10.1111/peps.12016

Wille, B., De Fruyt, F., \& Feys, M. (2010). Vocational interests and Big Five traits as predictors of job instability. Journal of Vocational Behavior, 76, 547-558. doi:10.1016/j.jvb.2010.01.007

Wille, B., De Fruyt, F., \& Feys, M. (2013). Big Five traits and intrinsic success in the new career era: A 15-year longitudinal study on employability and work-family conflict. Applied Psychology: An International Review, 62, 124-156. doi:10.1111/j.1464-0597.2012.00516.x

Wood, D., \& Roberts, B. W. (2006). Cross-sectional and longitudinal tests of the Personality and Role Identity Structural Model (PRISM). Journal of Personality, 74, 779-810. doi:10.1111/j.1467-6494.2006.00392.x
Woods, S. A., \& Hampson, S. E. (2010). Predicting adult occupational environments from gender and childhood personality traits. Journal of Applied Psychology, 95, 1045-1057. doi:10.1037/a0020600

Wothke, W. (2000). Longitudinal and multi-group modeling with missing data. In T. D. Little, K. U. Schnabel, \& J. Baumert (Eds.), Modeling londitudinal and multilevel data: Practical issues, applied approaches, and specific examples (pp. 219-240). Mahwah, NJ: Erlbaum.

Wrzesniewski, A., \& Dutton, J. E. (2001). Crafting a job: Revisioning employees as active crafters of their work. Academy of Management Review, 26, 179-201.

Wu, C.-H., \& Griffin, M. A. (2012). Longitudinal relationships between core self-evaluations and job satisfaction. Journal of Applied Psychology, 97, 331-342. doi:10.1037/a0025673

Received December 19, 2012

Revision received August 2, 2013 Accepted September 16, 2013 